\title{
Debt, Innovation, and Growth*
}

\author{
Thomas Geelen $^{\dagger} \quad$ Jakub Hajda $\quad$ Erwan Morellec ${ }^{\S}$
}

February 28, 2019

\section{Preliminary and Incomplete Do Not Circulate}

\begin{abstract}
Recent empirical studies show that innovative firms heavily rely on debt financing. This paper develops a Schumpeterian growth model in which firms' dynamic R\&D, investment, and financing choices are jointly and endogenously determined. It then investigates the relation between debt financing and innovation and growth. The paper features a rich interaction between firm policies and predicts substantial intra-industry variation in leverage and innovation, consistent with the empirical evidence. It also demonstrates that while debt hampers innovation by incumbents due to debt overhang, it also stimulates entry, thereby fostering innovation and growth at the aggregate level.
\end{abstract}

\footnotetext{
${ }^{*}$ We would like to thank Julien Cujean, Luca Mazzone (discussant), Johan Walden, and seminar participants at the SFI Research Days 2018 and Copenhagen Business School. Support from the Swiss Finance Institute and the Center for Financial Frictions (FRIC), grant no. DNRF102, is gratefully acknowledged.

${ }^{\dagger}$ Copenhagen Business School and Danish Finance Institute. E-mail: tag.fi@cbs.dk

${ }^{\ddagger}$ HEC Lausanne and Swiss Finance Institute. E-mail: jakub.hajda@unil.ch

§EPF Lausanne, Swiss Finance Institute, and CEPR. E-mail: erwan.morellec@epfl.ch.
} 


\section{Introduction}

Over the last few decades, the US economy has become innovation driven. Public firms now spend twice as much on on research and development than on capital expenditures and fixed assets have fallen from 34\% to less than 20\% of total assets between 1975 and 2016 (see for example Doidge, Kahle, Karolyi, and Stulz (2018)). Schumpeterian creative destruction has been a driving force of this transition to a knowledge-based economy. A good example of this phenomenon is Apple's swift rise to power in the mobile phone industry, replacing Nokia as the market leader. This example of creative destruction was driven by Apple's innovative success, even though both firms devoted large amounts of resources to R\&D.
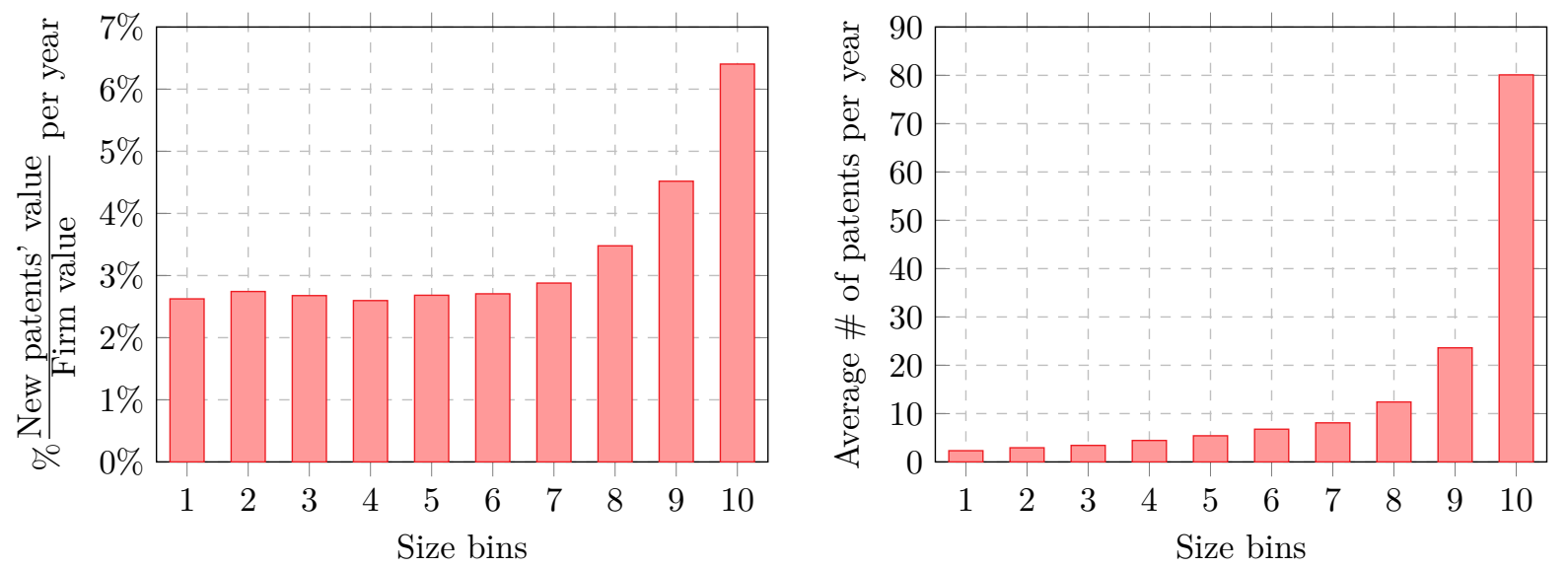

Figure 1: Innovation quality and intensity. The innovation data is based on Kogan, Papanikolaou, Seru, and Stoffman (2017) and the firm size data is from Compustat. The averages are conditional on issuing a new patent.

As shown in Figure 1, large firms play an important role for aggregate levels of innovation. Decades of empirical research have shown that outside debt is a key source of financing for these firms; see e.g. Graham, Leary, and Roberts (2015). In addition, even though debt is widely cast as an unlikely way to fund young and risky ventures, recent empirical studies show that small and young firms also heavily rely on debt financing. For example, Robb and Robinson (2014) find that formal debt financing (business bank loans, credit lines, and owner-backed bank loans) provide about $40 \%$ of a firm's initial startup capital. The reliance on formal credit channels holds true even for the smallest firms at the earliest stages of founding. Looking only at those firms that access equity sources, such as venture capital or 
angel financing, the average firm still has around $25 \%$ of its capital structure in the form of outside debt. A recent study by Hochberg, Serrano, and Ziedonis (2017) further documents a widespread use of loans to finance technology startups, even in early stages of developments. Relatedly, Davis, Morse, and Wang (2018) find that venture debt is often a complement to equity financing, with over $40 \%$ of all financing rounds including some amount of debt. Ibrahim (2010) estimates that venture lenders, including leader Silicon Valley Bank and specialized nonbank lenders, supply roughly $\$ 5$ billion to start-ups annually. ${ }^{1}$

Given the change to an innovation-based economy and the heavy reliance of innovative firms on debt financing, a number of questions naturally arise. First, how does debt financing influence the quality and intensity of innovation at the firm level? Second, how does debt financing affect firm growth, firm turnover, and industry structure? Third, how do innovation and Schumpeterian creative destruction in turn feed back into firms' financing policies and leverage dynamics? Lastly, what are the implications of debt financing in innovative firms for creative destruction and aggregate levels of innovation and investment?

This paper attempts to answer these questions by developing a Schumpeterian growth model in which firms' innovation, investment, and financing policies are jointly and endogenously determined. In this model, each incumbent has a portfolio of products and invests in R\&D. Firms simultaneously expand into new product lines when R\&D is successful and lose some of their product lines to other firms through competition. The force of creative destruction therefore affects firms R\&D policies, as each product remains profitable until it is overtaken by another firm's innovation. Firms decide on both R\&D intensity, that is the rate at which they generate new innovations, and $R \& D$ quality, that is the expected number of products that each innovation creates. Shareholders' choice of R\&D therefore determines firms' cash flow dynamics and risk, which feeds back into their financing decisions. That is, financial structure decisions are made simultaneously with technology and risk choices, in line with the evidence in MacKay and Phillips (2005).

In the model, firms are financed with equity and debt and determine their optimal leverage ratio by balancing the tax benefits of debt against default costs and potential distortions in

\footnotetext{
${ }^{1}$ This literature generally shows that while it is the case that start-ups cannot typically obtain debt financing from traditional banks, major U.S. banking institutions, public firms, and private firms specialize in providing loans to the very start-ups that traditional banks turn away.
} 
R\&D and investment due to debt financing. The policy choices are such that firms that perform well releverage to exploit the debt tax shields embedded in shareholders' equity stake. Firms that perform poorly default on debt and exit. Since debt and R\&D policies are not ex-ante contractible, conflicts of interests between shareholders and debtholders distort R\&D and financing choices. The model implies specific investment and leverage dynamics for each firm, given the model parameters for the technology, tax, and legal environment.

After solving for individual R\&D, investment, and financing choices, we embed the individual firm model into a Schumpeterian industry equilibrium in which the rate of creative destruction is determined endogenously. We derive a steady state equilibrium in which any new product line replaces an existing one and entrants replace incumbents that default and exit the industry. Firms in this equilibrium exhibit a wide variation in leverage, size, and innovation rates. Furthermore, all industry-wide equilibrium variables are constant over time, although individual firms continue innovating, investing, and adjusting their capital structure. In this equilibrium, capital structure and R\&D influence each other through three main channels. First, R\&D policy influences firms' risk profile, which in turn affects their capital structure decisions. Second, leveraged firms can be subject to debt overhang, which alters their incentives to innovate. Third, firms' individual R\&D and capital structure decisions influence aggregate levels of creative destruction and therefore of competition, which feeds back into their individual policy choices.

Starting with firm-level policies, we find that there is significant interaction between leverage and innovation. Notably, high levels of debt lead to less innovation by incumbents due to debt overhang. The effect of debt on innovation is sizeable and larger for firms with fewer products. It is also larger for firms that face larger financing frictions. Moreover, R\&D policies as well as the industry rate of creative destruction influence capital structure decisions. Crucially, firms' R\&D policy can alter the probability of default and depend on the rate of creative destruction. Thus, both play a role in determining firms' capital structure choices. Our model thus features a rich interaction between R\&D, investment, and financing decisions and predicts substantial intra-industry variation in leverage and innovation, consistent with the empirical evidence (see e.g. MacKay and Phillips (2005) and Kogan, Papanikolaou, Seru, and Stoffman (2017)). 
A key result of the paper is to demonstrate that, at the aggregate level, debt financing fosters innovation and creative destruction. This is the outcome of two opposite forces. First, as discussed above, innovation and investment by incumbents are negatively associated with debt. This effect is quantitatively large in the static debt model, in which debt overhang is severe. Allowing firms to refinance dampens these effects by allowing firms to take on less debt initially. Second, while debt hampers innovation and investment by incumbents, it also increases the value of incumbents and leads to a higher rate of creative destruction, which increases the entry rate. We demonstrate that the latter effect dominates at the aggregate level, implying that introducing debt financing in our standard endogenous growth model increases innovation and creative destruction and fosters growth.

We also illustrate how conclusions reached in the single-firm model, when ignoring equilibrium feedback effects, can be fundamentally altered, or even reversed, when the rate of creative destruction is endogenized. Consider for example the effects of innovation costs on equilibrium quantities. Increasing innovation costs leads to a drop in the level of innovation and in the value of future innovations. This reduces the cost of debt and leads firms to increase financial leverage. These effects are much stronger in a single-firm model that does not incorporate the feedback from the industry. Indeed, an effect that is absent when ignoring industry dynamics is that the drop in innovation quantity and the increase in leverage feedback into the equilibrium rate of creative destruction. As shown in the paper, the effect on innovation is generally first order, leading to a negative relation between innovation costs and the rate of creative destruction. This decrease in the rate of creative destruction-and the corresponding increase in the expected productive life of product lines - spurs innovation, partly offsetting the higher innovation costs. Lastly, these mechanisms translate to a lower turnover rate as innovation costs increase, because the decrease in the rate of creative destruction compensates for the lower levels of innovation. By contrast, in the single-firm model in which industry feedback effects are ignored, the sharp increase in leverage due to increasing innovation costs leads to an increase in the turnover rate.

Our article contributes to several strands of the literature. First, we contribute to the literature studying innovation in Schumpeterian growth models. Schumpeterian growth theory has been widely used in the literature on innovation and industry structure and evolution; 
see for example Klette and Kortum (2004), Lentz and Mortensen (2008), Aghion, Akcigit, and Howitt (2014), Akcigit and Kerr (2018), and Acemoglu, Akcigit, Alp, Bloom, and Kerr (2018). However, to the best of our knowledge, this literature has not studied the effects of debt financing on innovation, Schumpeterian competition, and industry dynamics. This is relatively surprising given that innovative firms heavily rely on debt financing. Our paper fills this gap by extending the model proposed by Klette and Kortum (2004) to incorporate debt financing. ${ }^{2}$ In our model, firms hold debt and default, which influences their R\&D policies and the industry level of Schumpeterian creative destruction. Another departure from Klette and Kortum (2004) is that we introduce heterogeneity in the quality of innovations, which we show is key to match the patterns in Figure $1 .^{3}$

Second, our paper relates to the literature on dynamic capital structure choice initiated by Fischer, Heinkel, and Zechner (1989). Models in this literature generally maintain the Modigliani and Miller (1958) assumption that investment and financing decisions are independent by assuming that the assets of the firm are exogenously given. This allows them to focus solely on the liability side of the balance sheet (see for example Leland (1998), Goldstein, Ju, and Leland (2001), Strebulaev (2007), Morellec, Nikolov, and Schürhoff (2012), Glover (2016), Morellec, Nikolov, and Schürhoff (2017), or DeMarzo and He (2018)). Our paper advances this literature by endogenizing not only firms dynamic capital structure choices but also their investment policy. In line with the evidence in Chava and Roberts (2008), Giroud, Mueller, Stomper, and Westerkamp (2012), or Favara, Morellec, Schroth, and Valta (2017), we find that debt financing has a negative effect on innovation and investment at the firm level, due to debt overhang (Myers (1977)). The distortions in investment due to debt financing are large and imply important feedback effects of (endogenous) investment on dynamic capital structure choice. An additional contribution with respect to this literature is that we embed the individual firm choices into a Schumpeterian industry equilibrium. We show that while debt financing hampers investment at the firm level, it increases aggregate

\footnotetext{
${ }^{2}$ Klette and Kortum (2004), Lentz and Mortensen (2008), and Akcigit and Kerr (2018) show that this setup exhibits many behaviors consistent with the applied micro literature.

${ }^{3}$ Akcigit and Kerr (2018) also introduce heterogeneity in the Klette and Kortum (2004) model while maintaining the assumption that firms are all-equity financed. In their model firms choose their level of internal and external R\&D, which leads to quality improvements on a single product of varying size. Instead firms choose the quality of innovations in our model, which determines the distribution over the number of products the firm improves.
} 
investment by stimulating creative destruction and entry.

Third, our paper relates to the literature on debt in industry equilibrium. Important contributions to this literature include Fries, Miller, and Perraudin (1997) and Zhdanov (2007), which respectively study static and dynamic capital structure choices in the Leahy (1993) model. In these models, incumbent firms are exposed to a single industry shock. They all have the same assets and the same debt level and there is no investment. In a closely related paper, Miao (2005) builds a competitive equilibrium model in which firms face idiosyncratic technology shocks and can issue debt at the time of entry before observing their profitability. In this model, all firms have the same debt level. However, the model has heterogeneity in firm size because firms are allowed to invest after entry. An important assumption in Miao (2005) is that there are no costs of adjusting capital. As a result, there is no debt overhang in the sense of Myers (1977) because the absence of adjustment costs or frictions make investment independent of financing (see also Manso (2008)). ${ }^{4}$ By contrast, in our model firms have different (endogenous) debt levels and can adjust capital structure after entry as profitability evolves. In addition, investment and financing decisions interact, leading to debt overhang and underinvestment by incumbents. ${ }^{5}$

Lastly, our paper relates to the growing literature on innovation and asset pricing. Important contributions to this literature include Garleanu, Panageas, and Yu (2012), Bena, Garlappi, and Grüning (2015), Kung and Schmid (2015), Kogan, Papanikolaou, and Stoffman (2018), or Garleanu and Panageas (2018). Most of these models are based on the expanding product variety model of Romer (1990), in which innovation is exogenous and there is no equilibrium feedback between R\&D incentives and valuations. Because our focus is on the relation between debt financing and endogenous innovation and growth, we follow instead the recent endogenous growth literature discussed above by focusing on Schumpeterian competition. Importantly, Schumpeterian models can feature high competition and high economic growth, which is a key channel at work in our model, while competition always lowers growth in the expanding product variety models, which is counterfactual.

\footnotetext{
${ }^{4}$ In Miao (2005) firms underinvest in that levered firms exit the industry at a higher rate than unlevered firms would. This feature is also present in our model.

${ }^{5}$ In related research, Malamud and Zucchi (2017) develop a model of firms' cash holdings, innovation, and aggregate growth in the presence of Schumpeterian competition. Their model assumes that firms are all equity financed.
} 
This article is organized as follows. Section II describes an individual firm model and then embeds it into a Schumpeterian industry equilibrium. Section III analyzes the model implications for the relation between innovation and debt financing. Section IV closes the model in geeral equilibrium. Section V concludes. Technical developments are gathered in the Appendix

\section{Model}

We present the model in steps, starting with the investment and financing decisions for an individual firm. We then embed this single firm model into an industry equilibrium.

\section{A Assumptions}

Throughout the paper, time is continuous and shareholders and creditors are risk neutral and discount cash flows at a constant rate $r>0$. The economy consists of a unit mass of differentiated goods that are produced by incumbent firms.

A firm is defined by the portfolio of goods it produces. The discrete number of different products supplied by any given firm at time $t \geq 0$, denoted by $P_{t}$, is defined on the integers and is bounded from above by $\bar{p}$. As a result of competition between firms, each good is produced by a single firm and yields a profit flow of one. Its value and the profit flow of the firm evolve through time as a birth-death process that reflects product creation and destruction.

To increase the number of goods it produces, a firm invests in innovative effort, i.e. spends resources on R\&D. A firm's R\&D choice is two-dimensional. Each instant, it chooses both the frequency of arrival of new innovations $\lambda_{t} \in[0, \bar{\lambda}]$ and the quality of new innovations $\theta_{t} \in[0,1]$. The arrival intensity of a new innovation $\lambda$, determines the Poisson rate at which innovations arrive. Conditional on an innovation, the number of new product lines that this innovation generates is

$$
X_{t}=\min \left(Y_{t}, \bar{p}-P_{t^{-}}\right) \text {with } Y_{t} \sim \operatorname{Bin}(n, \theta),
$$


where $n$ is an exogenous upper bound on the number of new product lines that can be developed following an innovation, $\theta$ measures the expected quality of the innovation, and $\operatorname{Bin}(n, \theta)$ is the binomial distribtion. The expected number of new product lines is approximately given by $n \theta$. Therefore, a higher quality $\theta$ leads to a higher expected number of new product lines. Bounding the number of new product lines $X_{t}$ from above by $\bar{p}-P_{t^{-}}$ensures that $P_{t}$ never exceeds $\bar{p}$. The total number of product lines the firm has developed up to time $t$, denoted by $I_{t}$, evolves as

$$
d I_{t}=X_{t} d N_{t}^{I}
$$

where $d N_{t}^{I}$ is a Poisson process with intensity $\lambda_{t}$.

A firm's existing product lines can become obsolete because some other firm innovates on a good it is currently producing. In this case, the incumbent producer loses the good from its portfolio due to Schumpeterian creative destruction. Since any firm is infinitesimal, we can ignore the possibility that it innovates on a good it is currently producing. Each product becomes obsolete at an exponentially distributed time with intensity $f$. We call $f$ the rate of creative destruction, that each firm takes as given and is constant over time. Subsection $\mathrm{C}$ embeds the individual firm model into an industry equilibrium and endogenizes the rate $f$ of creative destruction. The total number $O_{t}$ of product lines lost by the firm up to time $t \geq 0$ because of creative destruction evolves as

$$
d O_{t}=d N_{t}^{O}
$$

where $d N_{t}^{O}$ is a Poisson process with intensity $f P_{t^{-}}$. The total number product lines in a firm's portfolio $P_{t}$ is therefore given by

$$
P_{t}=I_{t}-O_{t}
$$

A firm with zero product lines exits the economy.

A firm performing R\&D with intensity and quality $\left(\lambda_{t}, \theta_{t}\right)$ incurs flow costs $q\left(P_{t}, \lambda_{t}, \theta_{t}\right)$. To ensure that shareholders are better off with more product lines we impose that the R\&D 
cost function does not increase too fast in the number of product lines, in that

$$
q(p+1, \lambda, \theta)-q(p, \lambda, \theta)<1
$$

An incumbent firm's operating profit is the profit that comes from the operation of the product lines minus the costs of performing R\&D:

$$
P_{t}-q\left(P_{t}, \lambda_{t}, \theta_{t}\right)
$$

Profits are taxed at the constant rate $\pi>0$. As a result, firms have an incentive to issue debt to reduce corporate taxes. To stay in a simple time-homogeneous setting, we follow the literature (e.g. Leland (1994), Leland (1998), and Duffie and Lando (2001)) and consider debt contracts that are characterized by a perpetual flow of coupon payments $c$. The firm incurs a proportional cost $\xi$ when issuing debt. The proceeds from the debt issue are distributed on a pro rata basis to shareholders at the time of issuance. Firms whose conditions deteriorate may default on their debt obligations, which happens at time $\tau_{D}$, leading to liquidation. Default risk leads to potential distortions in the firm's R\&D decisions reflecting debt overhang. In addition, a fraction $\alpha$ of asset value is lost as a frictional cost at the time of default. When choosing the amount of debt, shareholders balance the tax benefits of debt against its costs. Subsection D allows firms to dynamically change their capital structure.

As in Klette and Kortum (2004), a mass of entrants invests in R\&D to become producers upon a successful innovation. When an entrant generates a new innovation, it becomes an incumbent. Similarly to an incumbent, the entrant chooses its R\&D intensity $\lambda_{t}$ and quality $\theta_{t}$. The entrant has an $\mathrm{R} \& \mathrm{D}$ cost function $q_{e}(\lambda, \theta)$. Because an entrant has no product lines before becoming an incumbent, its optimal strategy is time-homogenous: $\lambda_{t}=\lambda_{e}$ and $\theta_{t}=\theta_{e}$. Entrants are all-equity financed before entry. Indeed, issuing debt is suboptimal for these firms because they have no taxable income. After the entrant has an innovative breakthrough and knows how many product lines this breakthrough generates, it has the possibility to issue debt. Entrants pay the entry cost $H$ upon entering the market.

The life cycle of a firm is presented in Figure 2. A firm is at first an all-equity financed 


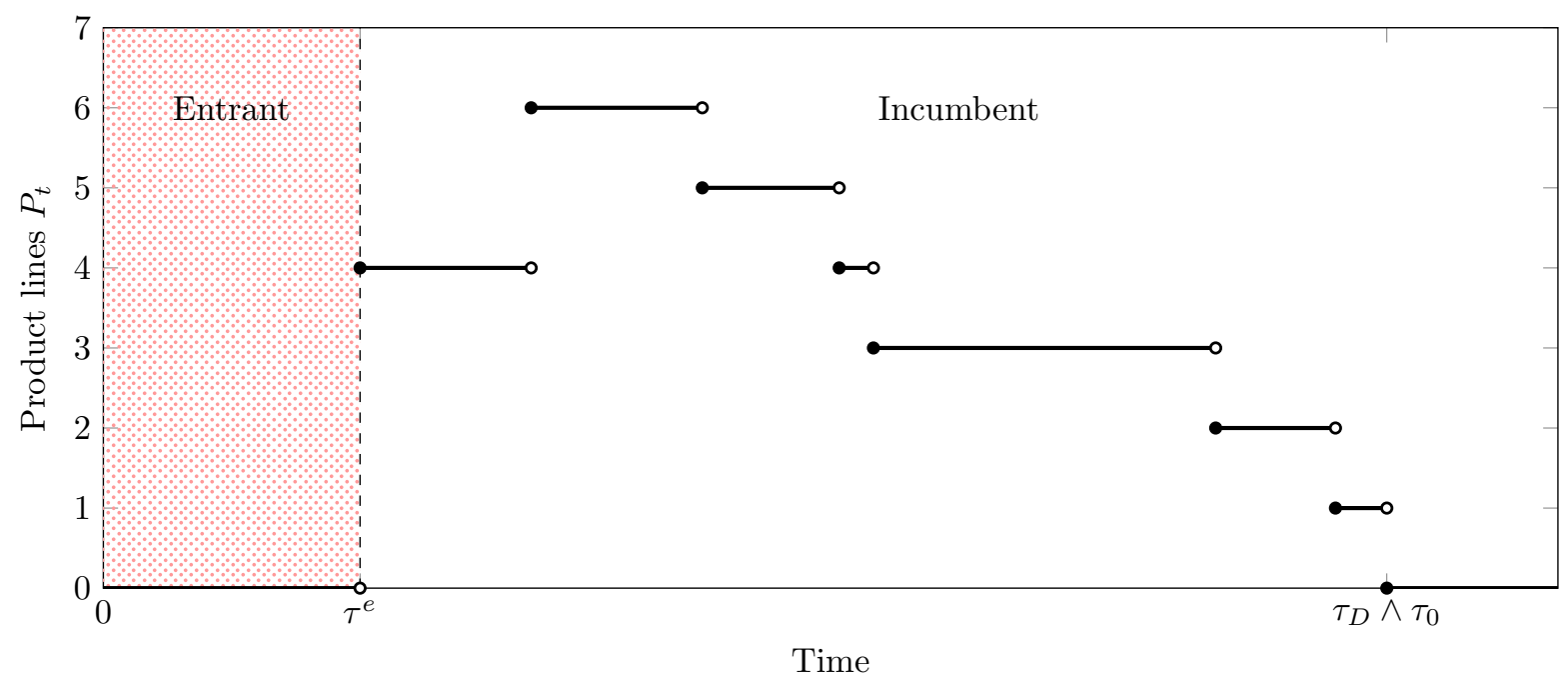

Figure 2: Life-cycle of a firm. The firm starts as an entrant and becomes an incumbent (with 4 product lines) at $\tau_{E}$. The number of product lines then evolve over time and the firm defaults at $\tau_{D} \wedge \tau_{0}$.

entrant, which incurs R\&D expenses until it innovates for the first time. At $\tau^{e}$, the entrant experiences a breakthrough resulting in new product lines and becomes an incumbent. Once the firm enters, it generates profits from its portfolio of products and continues to make $R \& D$ decisions, which influences the intensity at which new innovations arrive as well as their quality. This process continues until default.

\section{B Optimal Financing and Investment}

We start by analyzing the case in which debt policy is static (as in e.g. Leland (1994) and Duffie and Lando (2001)) and consider a firm that initially issues a perpetual debt contract with coupon $c$. In our model, the value-maximizing level of debt is determined by balancing the tax benefits of debt with issuance, default, and underinvestment costs. That is, the presence of debt can lead to default, which potentially distorts the firm's R\&D decisions.

We solve the model recursively, starting with the value of levered equity for a given financing policy. Since each good generates the same flow of profits, we only need to keep track of the number of goods it produces and the coupon when describing the state of the firm. Let $\tau_{D}$ be the time at which the firm defaults. After debt has been issued, shareholders maximize equity value by choosing the firm's default and R\&D policy. As a result, the equity 
value for a given coupon $c$ satisfies

$$
E(p, c)=\sup _{\left\{\lambda_{t}, \theta_{t}\right\}_{t \geq 0}, \tau_{D}} \mathbb{E}_{p}\left[\int_{0}^{\tau_{D} \wedge \tau_{0}} e^{-r t}(1-\pi)\left(P_{t}-c-q\left(P_{t}, \lambda_{t}, \theta_{t}\right)\right) d t\right]
$$

where $\mathbb{E}_{p}[\cdot]=\mathbb{E}_{0}\left[\cdot \mid P_{0}=p\right], \tau_{0}$ is the first time the firm has zero product lines, and $x \wedge y=$ $\inf \{x, y\}$. As shown by equation (2), shareholders receive the after-tax profits from $P_{t}$ product lines minus the coupon payments $c$ and R\&D expenses $q\left(P_{t}, \lambda_{t}, \theta_{t}\right)$ until they decide to default. They pick the R\&D strategy $\left\{\lambda_{t}, \theta_{t}\right\}_{t \geq 0}$ and default time $\tau_{D}$ to maximize the equity value. The presence of debt as well as the rate of creative destruction alter shareholders' incentives to invest in $R \& D$ or to continue operations.

From equation (2), it follows that the equity value solves the following Hamilton-JacobiBellman equation

$$
\begin{aligned}
r E(p, c)=\sup \{0, & (1-\pi)(p-c) \\
& +\underbrace{\sup _{\lambda, \theta}\left\{\lambda\left(\mathbb{E}^{\theta}[E(\min \{p+x, \bar{p}\}, c)]-E(p, c)\right)-(1-\pi) q(p, \lambda, \theta)\right\}}_{\text {RED }} \\
& +\underbrace{f p(E(p-1, c)-E(p, c))}_{\text {Creative destruction }}\},
\end{aligned}
$$

where $\mathbb{E}^{\theta}$ takes the expectation over $x \sim \operatorname{Bin}(n, \theta)$ and $E(0, c)=0$. We then have the following result.

Theorem 1 (Equity Value). A unique solution to the equity value (2) exists. Equity value is non-decreasing in $p$ and therefore the optimal default strategy is a barrier default strategy $\tau_{D}=\inf \left\{t>0 \mid P_{t} \leq p_{D}\right\}$. If the optimal level of RED is interior $((\lambda, \theta) \in(0, \bar{\lambda}) \times(0,1))$, it solves

$$
\begin{aligned}
\mathbb{E}^{\theta}[E(\min \{p+x, \bar{p}\}, c)]-E(p, c) & =(1-\pi) \frac{\partial q(p, \lambda, \theta)}{\partial \lambda}, \\
\lambda \frac{\partial \mathbb{E}^{\theta}[E(\min \{p+x, \bar{p}\}, c)]}{\partial \theta} & =(1-\pi) \frac{\partial q(p, \lambda, \theta)}{\partial \theta} .
\end{aligned}
$$

The optimal R\&D strategy, if interior, balances the marginal benefits of R\&D (left-hand 
side) and the marginal costs of $\mathrm{R} \& \mathrm{D}$ (right-hand side). The marginal cost depends on the $\mathrm{R} \& \mathrm{D}$ cost function $q(p, \lambda, \theta)$. If an innovation arrives, the increase in equity value is

$$
\underbrace{\mathbb{E}^{\theta}[E(\min \{p+x, \bar{p}\}, c)]}_{\text {Post innovation }}-\underbrace{E(p, c),}_{\text {Pre innovation }}
$$

which is the marginal gain from increasing the arrival rate of innovations $\lambda$. Similarly, higher R\&D quality $\theta$ increases the expected number of new product lines when an innovation arrives. The increase in equity value from higher $R \& D$ quality $\theta$ (multiplied by the probability of occurrence of an innovation $\lambda$ ) is

$$
\lambda \frac{\partial \mathbb{E}^{\theta}[E(\min \{p+x, \bar{p}\}, c)]}{\partial \theta} .
$$

The presence of debt in the firm's capital structure implies that shareholders do not fully capture the benefits of investment, which in turn implies that the level of $R \& D$ that maximizes shareholder value is lower in a levered firm. Section III provides a detailed analysis of the effects of debt financing on R\&D.

We also perform a comparative statics analysis with respect to the model's parameters:

Proposition 1 (Comparative Statics). If $E(p, c)>0$, equity value is decreasing in the tax rate $\pi$, the coupon $c$, the rate of creative destruction $f$, and the cost $q(p, \lambda, \theta)$ of performing $R E D$.

An increase in all of these parameters makes the firm less profitable, thereby reducing the equity value.

After the entrant has an innovative breakthrough and knows how many product lines $p_{0}$ this breakthrough generates, it has the possibility to issue debt. Given the rate of creative destruction $f$ and shareholders' optimal $\mathrm{R} \& \mathrm{D}\left\{\lambda_{t}, \theta_{t}\right\}_{t \geq 0}$ and default $\tau_{D}$ policies, the debt value $D(p, c)$ is the discounted value of the coupon payments until the time of default plus the present value of the cash flow in default. That is, we have

$$
D(p, c)=\mathbb{E}_{p}\left[\int_{0}^{\tau_{D} \wedge \tau_{0}} e^{-r t} c d t+e^{-r \tau_{D}} \mathbb{I}_{\left\{\tau_{D} \leq \tau_{0}\right\}}(1-\alpha) \frac{(1-\pi) P_{\tau_{D}}}{r+f}\right] .
$$


Let $\tau_{e}$ be the time at which the entrant has a breakthrough and can develop its first product lines, which happens with intensity $\lambda_{e}$. The entrant's shareholders pick the R\&D intensity and quality that maximize their equity value, which consists of the proceeds once there is a breakthrough minus the tax-deductible $R \& D$ costs. That is, we have

$$
\begin{aligned}
E^{e}(f) & =\sup _{\lambda_{e}, \theta_{E}} \mathbb{E}_{0}\left[e^{-r \tau_{e}} V\left(f, \theta_{e}\right)-\int_{0}^{\tau_{e}} e^{-r t}(1-\pi) q_{e}\left(\lambda_{e}, \theta_{e}\right) d t\right] \\
& =\sup _{\lambda_{e}, \theta_{e}}\left(\frac{\lambda_{e} V\left(f, \theta_{e}\right)-(1-\pi) q_{e}\left(\lambda_{e}\right)}{r+\lambda_{e}}\right),
\end{aligned}
$$

where

$$
V\left(f, \theta_{e}\right)=\mathbb{E}^{\theta_{e}}\left[\sup _{c \geq 0}\left\{E\left(p_{0}, c\right)+(1-\xi) D\left(p_{0}, c\right)\right\}\right],
$$

with $p_{0}=\min (x, \bar{p})$ and $x \sim \operatorname{Bin}\left(n, \theta_{e}\right)$. As shown by equation (6), shareholders select the coupon that maximizes the value of their claim when entering the industry.

To enter the market, entrants' shareholders pay the entry cost $H>0$. The free entry condition then implies that

$$
E^{e}(f) \leq H,
$$

which becomes an equality when there is a positive mass of entrants.

\section{Industry Equilibrium}

This section incorporates the individual-firm decisions into a Schumpeterian industry equilibrium. We look for a Markovian steady state industry equilibrium in which the number of firms and product lines is constant over time. In this industry equilibrium, both incumbents and entrants maximize their equity value. That is, incumbents optimally choose their R\&D and default decisions and entrants optimally choose their R\&D and capital structure decisions. Given that we look for a Markovian steady state equilibrium, incumbents' optimal policies are a function of the number of product lines they own and their coupon, which is a function of the number of product lines at entry $p_{0}$. Entrants' optimal policies are time- 
homogenous. Finally, the free entry condition ensures that new entrants continue to enter as long as entry is profitable.

Definition 1. (Industry Equilibrium) The parameters and policies

$$
\Psi^{*}=\left\{f^{*}, c^{*}\left(p_{0}\right), \lambda^{*}\left(p \mid p_{0}\right), \theta^{*}\left(p \mid p_{0}\right), p_{D}^{*}\left(p_{0}\right), \lambda_{e}^{*}, \theta_{e}^{*}\right\}
$$

are an industry equilibrium if:

1. Incumbents: Given the rate of creative destruction $f^{*}$ and coupon $c^{*}\left(p_{0}\right)$, incumbents level of $\operatorname{RED}\left(\lambda^{*}\left(p \mid p_{0}\right), \theta^{*}\left(p \mid p_{0}\right)\right)$ and default decision $p_{D}^{*}\left(p_{0}\right)$ maximize shareholder value.

2. Entrants: Given the rate of creative destruction $f^{*}$, entrants level of $\operatorname{RED}\left(\lambda_{e}^{*}, \theta_{e}^{*}\right)$ and capital structure upon becoming an incumbent $c^{*}\left(p_{0}\right)$ maximize shareholder value.

3. Entry: The free entry condition holds:

$$
E^{e}\left(f^{*}\right) \leq H,
$$

and the inequality binds when there is creative destruction $f^{*}>0$.

Figure 3 illustrates an industry equilibrium in which new product lines replace existing ones and entrants replace incumbents that default and exit the industry. The size of the circles indicates the mass of firms of each type. In a steady state equilibrium, the size of these circles is constant over time. Incumbents can move up due to innovations, which generate new product lines, and move down due to creative destruction. Because an innovation can generate more than one product line and the number of product lines generated is random, there are multiple upward flows. In this equilibrium firms exit when they have zero product lines and therefore there is a positive mass of entrants. All industry-wide variables are constant over time, even though individual firms can create new product lines, have existing product lines that become obsolete, and can even exit.

The following theorem establishes equilibrium existence: 


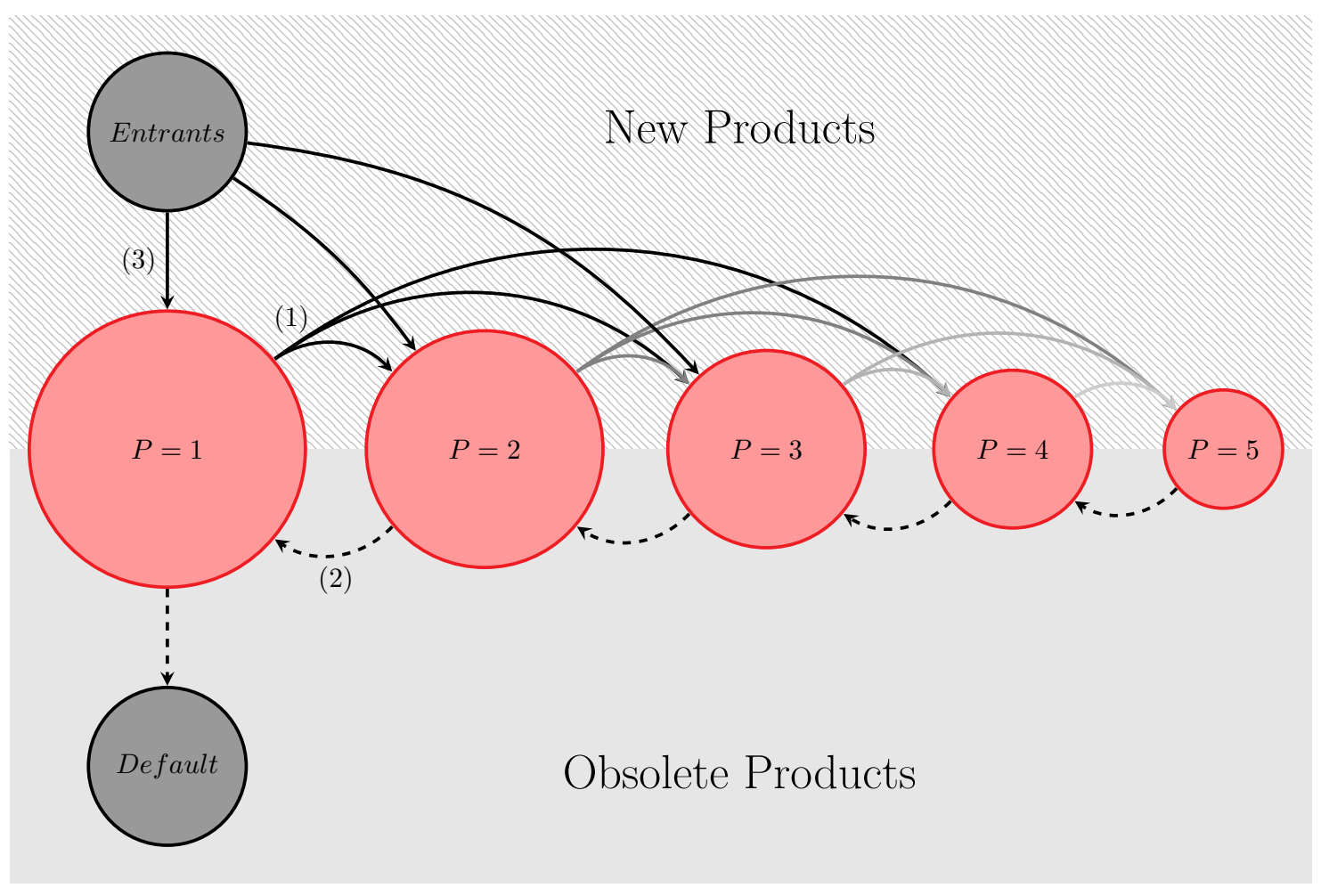

Figure 3: Steady state equilibrium. This figure gives an example of a steady state distribution in which there is entry.

Theorem 2 (Equilibrium Existence). If Assumption 1 in Appendix B holds then there exists an industry equilibrium $\Psi^{*}$.

Under additional conditions, we can establish that all equilibria with entry have the same rate of creative destruction $f^{*}$ :

Proposition 2. (Uniqueness of the Rate of Creative Destruction) If the debt value is strictly decreasing in $f$ then all equilibria have the same rate of creative destruction $f^{*}$.

The condition that the debt value is strictly decreasing in $f$ ensures that firm value is decreasing in $f$ and that a higher rate of creative destruction makes the firm worse off. Therefore, there can only exist one level of creative destruction for which the free entry condition binds.

We can also characterize the comparative statics with respect to the rate of creative destruction for an industry with all-equity financed firms: 
Proposition 3. (Comparative Statics: No debt case) Let $f_{\text {No Debt }}^{*}$ be the equilibrium rate of creative destruction in case incumbent firms are restricted to have no debt. The equilibrium rate of creative destruction in the No Debt case $f_{\text {NoDebt }}^{*}$ is non-decreasing in the tax rate $\pi$, incumbents' $R \mathscr{B} D$ cost $q(p, \lambda, \theta)$, entrants $R \mathscr{E} D$ cost $q_{E}(\lambda, \theta)$, and the entry cost $H$.

This theorem shows that a decrease in the cost of running a firm, e.g. lower taxes, $R \& D$ cost, and entry cost, lead to higher levels of creative destruction since entry becomes more profitable and therefore more attractive.

A similar argument shows that debt increases the rate of creative destruction since it increases firm value, which spurs entry and therefore innovation:

Proposition 4. (Debt versus No Debt) Let $f_{\text {No Debt }}^{*}$ be the equilibrium rate of creative destruction in case firms are restricted to have no debt. Then there exists an industry equilibrium with a rate of creative destruction

$$
f^{*} \geq f_{\text {No Debt }}^{*} .
$$

\section{The Effects of Refinancing}

This section extends the model by allowing firms to dynamically optimize their capital structure. Notably, firms that perform well may releverage to exploit the tax benefits of debt. For simplicity, we assume that firms can only reduce their indebtedness in default. ${ }^{6}$ We consider that firms can call their debt at price $\rho\left(p^{I}\right) c$ with $\rho\left(p^{I}\right)>0$, where $p^{I}$ is the number of product lines the firm had when it previously issued debt. The ability to buyback the debt for $\rho\left(p^{I}\right)$ implies that we have to keep track of the number of product lines the firm had the last time it issued debt $p^{I}$. We restrict the firm to refinance at most $K$ times. Therefore, we assume that $c \leq \bar{c}$. In this section we present the solution for the stationary case when $K \rightarrow \infty$. Our results also hold for any finite $K$.

\footnotetext{
${ }^{6}$ While in principle management can both increase and decrease debt levels, Gilson (1997) finds that transaction costs discourage debt reductions outside of renegotiation. Hugonnier, Malamud, and Morellec (2015) show in a Leland-type model that reducing debt is never optimal for shareholders if debt holders are dispersed and have rational expectations. That is, there is no deleveraging along the optimal path. See Admati, Demarzo, Hellwig, and Pfleiderer (2018) for a similar result in a two-period model.
} 
Define firm value as the equity value plus the debt value minus the issuance cost as:

$$
F\left(p, c, p^{I}\right)=E\left(p, c, p^{I}\right)+(1-\xi) D\left(p, c, p^{I}\right)
$$

The exact definition of the equity and debt value in case the firm can refinance its debt is given below. The payoff to shareholders of restructuring the firm's debt is given by the value of the firm after refinancing minus the cost of buying back the debt:

$$
\sup _{c^{\prime}>c} F\left(p, c^{\prime}, p\right)-\rho\left(p^{I}\right) c
$$

This implies that the equity value, with the possibility to dynamically optimize the firm's capital structure, is given by

$$
\begin{aligned}
E\left(p, c, p^{I}\right)=\sup _{\left\{\lambda_{t}, \theta_{t}\right\}_{t \geq 0}, \tau_{D}, \tau_{R}}\{ & \mathbb{E}_{p}\left[\int_{0}^{\tau_{D} \wedge \tau_{0} \wedge \tau_{R}} e^{-r t}(1-\pi)\left(P_{t}-c-q\left(P_{t}, \lambda_{t}, \theta_{t}\right)\right) d t\right] \\
& \left.+\mathbb{E}_{p}\left[\mathbb{I}_{\left\{\tau_{R}<\tau_{D} \wedge \tau_{0}\right\}} e^{-r \tau_{R}}\left(\sup _{c^{\prime}>c} F\left(P_{\tau_{R}}, c^{\prime}, P_{\tau_{R}}\right)-\rho\left(p^{I}\right) c\right)\right]\right\},
\end{aligned}
$$

where $\tau_{R}$ is the restructuring time chosen by shareholders. Shareholders receive the revenues generated by the portfolio of products minus the coupon payments, the R\&D cost, and corporate taxes until either the firm defaults or changes its capital structure. In default, equity value drops to zero. When refinancing, shareholders repurchase existing debt at price $\rho\left(p^{I}\right) c$ and obtain the (after issuance cost) optimal firm value with a larger coupon $F\left(P_{\tau_{R}}, c^{\prime}, P_{\tau_{R}}\right)$.

Debt value also takes into account the possibility that the firm refinances and is given by:

$$
\begin{aligned}
D\left(p, c, p^{I}\right)= & \mathbb{E}_{p}\left[\int_{0}^{\tau_{D} \wedge \tau_{0} \wedge \tau_{R}} e^{-r t} c d t+\mathbb{I}_{\left\{\tau_{D} \wedge \tau_{0} \leq \tau_{R}\right\}} e^{-r \tau D}(1-\alpha) \frac{(1-\pi) P_{\tau_{D} \wedge \tau_{0}}}{r+f}\right] \\
& +\mathbb{E}_{p}\left[\mathbb{I}_{\left\{\tau_{R}<\tau_{D} \wedge \tau_{0}\right\}} e^{-r \tau_{R}} \rho\left(p^{I}\right) c\right] .
\end{aligned}
$$

This equation shows that creditors receive coupon payments until either the firm defaults or refinances its debt. When the firm defaults $\left(\tau_{D} \wedge \tau_{0} \leq \tau_{R}\right)$, creditors get the present value of the firm cash flows net of the proportional default costs $\alpha$. When the firm refinances its debt $\left(\tau_{R}<\tau_{D} \wedge \tau_{0}\right)$, creditors get $\rho\left(p^{I}\right) c$. 
In the numerical analysis, we set $\rho\left(p^{I}\right)$ such that debt is called at par given that the firm issues debt with the firm value maximizing coupon $c^{*}(p) \in[0, \bar{c})$. The buyback price $\rho\left(p^{I}\right)$ therefore solves

$$
\rho(p) c^{*}(p)=D\left(p, c^{*}(p), p\right)
$$

where $c^{*}(p)$ is the optimal coupon given that the firm has $p$ product lines.

The entrant value is the same as in equation (5) with $V\left(f, \theta_{e}\right)$ defined as

$$
V\left(f, \theta_{e}\right)=\mathbb{E}^{\theta_{e}}\left[\sup _{c \geq 0}\left\{E\left(p_{0}, c, p_{0}\right)+(1-\xi) D\left(p_{0}, c, p_{0}\right)\right\}\right]
$$

An industry equilibrium is defined as before, except that firms' optimal policies additionally depend on the number of product lines the firm had the last time it issued debt $p^{I}$.

In the Appendix, we establish existence of the equity value, which is the equivalent of Theorem 1 in the model with static debt, and existence of an equilibrium

Theorem 3 (Equilibrium Existence with Debt Refinancing). If Assumption 1 in Appendix $C$ holds, then there exists an industry equilibrium $\Psi^{*}$ in the model with debt refinancing.

As in the case of a static debt policy, we can establish uniqueness under additional conditions:

Proposition 5 (Uniqueness of the Rate of Creative Destruction with Debt Refinancing). If the debt value is strictly decreasing in $f$ then all equilibria with debt refinancing have the same rate of creative destruction $f^{*}$.

\section{Model Analysis}

This section examines the implications of the model for innovation, financing policy, and industry dynamics. To do so, we calibrate the model to match the observed characteristics of innovation and capital structure policies of an average US public firm, using firms' financial data from Compustat and the data on firms' innovation activity from Kogan et al. (2017). 


\section{A Parameter values}

We first set the interest rate $r$ at $4.2 \%$ as in Morellec et al. (2012). We choose a tax rate $\pi$ of $15 \%$, consistent with the estimates of Graham (1996). The bankruptcy cost $\alpha$ is $45 \%$, which is the value estimated by Glover (2016). The cost of debt issuance $\xi$ is set to be $1.36 \%$, consistent with the evidence on debt underwriting fees in Altinkilic and Hansen (2000). We choose a cost function separable in R\&D intensity and quality, as in Akcigit and Kerr (2018). Notably, we assume that:

$$
\begin{aligned}
& q(p, \lambda, \theta)=p\left(\beta_{i}\left(\frac{\lambda}{p}\right)^{\frac{1}{\gamma_{i}}}+\beta_{q} \theta^{\frac{1}{\gamma_{q}}}\right) \\
& q_{E}(\lambda, \theta)=\beta_{i} \lambda^{\frac{1}{\gamma_{i}}}+\beta_{q} \theta^{\frac{1}{\gamma_{q}}}
\end{aligned}
$$

where $\beta_{q}=2 \beta_{i}$ and that $\gamma_{q}=\gamma_{i}=\gamma$. This specification captures the notion that investment in innovation quality is more expensive than investment in innovation intensity. To obtain the remaining parameter values, we focus on matching several key moments of interest in the data: the mean and variance of the leverage ratio, the mean of the innovation value per patent, and the turnover rate. Firms' choice of leverage is tightly linked to the parameters governing the R\&D cost function $\beta$ and $\gamma$. Furthermore, innovation quantity is directly linked to the maximum number of new products per innovation $n$. These parameters also determine the cost of performing $R \& D$ and are thus informative about the innovation value per patent. Lastly, the entry cost $H$ pins down the turnover rate. Panel A of Table 1 summarizes the baseline values of the parameters.

To compute the data counterparts of the model-implied variables, we use the Kogan, Papanikolaou, Seru, and Stoffman (2017) data on patent quantity and value merged with accounting variables from Compustat. We use the sample period 1980 - 2010. Furthermore, we apply standard Compustat filters and remove firms with negative book equity and marketto-book larger than 15. All variables are then winsorized at $1 \%$ and $99 \%$ in each fiscal year. Panel B of Table 1 presents the definitions of the moments of interest in the data as well as their model counterparts. We compute the model-implied moments by simulating a panel of firms similar to the ones observed in the data. We simulate a balanced panel of $N=15000$ 
firms over $T=15$ years. Firms that exit are replaced with new entrants to keep the panel balanced.

\begin{tabular}{|c|c|c|}
\hline \multicolumn{3}{|c|}{ Panel A: Baseline parameter values } \\
\hline Parameter & Symbol & Value \\
\hline Max \# products per firm & $\bar{p}$ & 25 \\
\hline Interest rate & $r$ & $4.2 \%$ \\
\hline Tax rate & $\pi$ & $15 \%$ \\
\hline Bankruptcy cost & $\alpha$ & $45 \%$ \\
\hline Debt issuance cost & $\xi$ & $1.36 \%$ \\
\hline Max \# new products per innovation & $n$ & 3 \\
\hline Entry cost & $H$ & 8 \\
\hline Innovation intensity: scale & $\beta_{i}$ & 27 \\
\hline Innovation intensity: curvature & $\gamma$ & 0.308 \\
\hline Innovation quality: scale & $\beta_{q}$ & 54 \\
\hline Innovation quality: curvature & $\gamma_{q}$ & 0.308 \\
\hline \multicolumn{3}{|c|}{ Panel B: Variable definitions } \\
\hline Moment & Model & Data \\
\hline Leverage & $\frac{D_{t}}{D_{t}+E_{t}}$ & $\frac{d l t t_{t}+d l c_{t}}{d l t t_{t}+d l c_{t}+p r c c \_f_{t} * c s h o_{t}}$ \\
\hline Innovation value per patent & $\frac{E\left(P_{t}+n\right)-E\left(P_{t}\right)}{n E\left(P_{t}\right)}$ & $\frac{t s m_{t}}{{\operatorname{prcc} \_f_{t} * c s h o_{t} * \text { fnpats }_{t}}}$ \\
\hline Innovation quantity & $\max \left(P_{t}-P_{t-1}, 0\right)$ & fnpats $_{t}$ \\
\hline Tax benefit & $\frac{\mathbb{E}[\pi D]}{\mathbb{E}[V]}$ & \\
\hline Agency cost & $\mathbb{E}\left[\frac{V_{\text {first-best }}-V}{V_{\text {first-best }}}\right]$ & \\
\hline
\end{tabular}

Table 1: Baseline parameter values and definitions of model-implied and data moments.

\section{B Baseline calibration and model-implied moments}

We calibrate the static version of the model and report the model-implied variables in Table 2. The numbers suggest that the model succeeds in replicating the magnitude of observed financing and innovation policies. In particular, the average (market) leverage ratio is equal to $20 \%$ in the dynamic debt specification and to $25 \%$ in the static debt specification, both of which are close to the observed value of $22 \%$. As we will show later on, the relatively low value of leverage in the model is the result of the endogenous rate of creative destruction 
that disciplines firms' financing policy. The model also matches the variance of leverage, which equals $1.8 \%$ in the data, thus generating sizeable variation in financing policy. The average innovation quality per patent is close to the observed value of $0.5 \%$, and the average innovation quantity (not reported in the table) is 2.26, which is close to the value of 3.95 implied by the data. The model generates a turnover rate of $0.8 \%$, which is close to the observed turnover rate of 1\%, reported by Corbae and D'Erasmo (2017).

\begin{tabular}{lcccccc}
\hline \multicolumn{7}{c}{ Baseline calibration. All values are in \%. } \\
\hline & $\begin{array}{c}\text { Leverage } \\
\text { Mean }\end{array}$ & $\begin{array}{c}\text { Leverage } \\
\text { Variance }\end{array}$ & $\begin{array}{c}\text { Value p.p. } \\
\text { Mean }\end{array}$ & $\begin{array}{c}\text { Tax } \\
\text { benefit }\end{array}$ & $\begin{array}{c}\text { Agency } \\
\text { cost }\end{array}$ & $\begin{array}{c}\text { Turnover } \\
\text { rate }\end{array}$ \\
\hline No debt & 0.00 & 0.00 & 0.46 & 0.00 & 0.00 & 0.28 \\
Static debt & 25.06 & 2.25 & 0.46 & 3.76 & 0.88 & 0.81 \\
Static debt, fixed $f$ & 25.88 & 2.31 & 0.45 & 3.88 & 0.73 & 0.73 \\
Dynamic debt & 20.71 & 2.97 & 0.44 & 3.11 & - & 0.74 \\
\hline
\end{tabular}

Table 2: Baseline calibration of the model.

Table 2 contains the baseline calibration of the model, as well as the model-implied moments in the 'Dynamic debt' and 'No debt' cases. The table also contains the 'Fixed $f$ ' specification in which the firm issues debt but the rate of creative destruction $f$ is not determined endogenously, but rather fixed at the level implied by the 'No debt' specification. A comparison between the baseline and 'No debt' case indicates that debt lowers the outcomes of firms' R\&D investment, and facilitates firm exit. Comparing the firm values in the baseline static debt case and in the 'Static debt first-best' case, in which firms choose their R\&D policy by maximizing the firm value rather than the equity value and take the optimal coupon as given in the static debt case, implies an agency cost of debt of $0.88 \%$.

The values of the model-implied variables reveal that there are substantial differences between the static and dynamic specification. In particular, when firms are allowed to refinance later on, they adopt lower leverage ratios, as they tend to optimally refinance when they grow larger. This mitigates the debt overhang problem and results in higher levels of R\&D innovation than in the static debt case. This translates into larger firms, on average, and thus into a smaller turnover rate than in the static case.

The results highlight that firms benefit substantially from debt financing: the implied net benefits of debt are around $3.76 \%$ of firm value, which is close to the estimates of Korteweg 


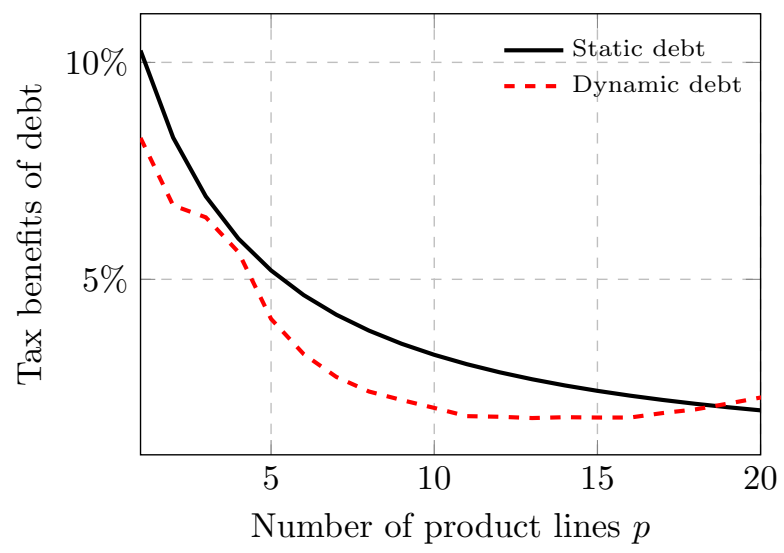

Figure 4: Average tax benefits by $p$. The tax benefits of debt are expressed as $\%$ of firm value.

(2010) or van Binsbergen, Graham, and Yang (2010). Figure 4 shows that the benefits of debt vary with firm size, with firm with more product lines benefitting relatively less from the tax benefits.

\section{Investment and financing policy}

In the model, firms determine their investment policy by balancing the benefits and costs associated with each type of $R \& D$ investment. Firms increase investment in innovation intensity $\lambda$ and quality $\theta$ as long as the marginal benefits outweigh the marginal costs. The marginal benefits follow from the cash flow generated by new product lines and the marginal costs are the cost associated with performing R\&D.

Shareholders pick a leverage ratio that balances the marginal benefits and marginal cost of debt. Interest expenses on debt are tax deductible, which gives shareholders an incentive to issue debt. The presence of debt gives shareholders an option to default, which is costly.

Debt also reduces the benefits of innovation to shareholders because part of the benefits of investment accrue to creditors. Therefore, debt distorts innovation incentives and leads to underinvestment. These distortions in innovation policy then feed back into firms' cash flow dynamics which influences the turnover rate and therefore the optimal leverage choice. Firms' investment and financing policy are therefore jointly determined. We illustrate these mechanisms below. 
Comparative statics. All values are in $\%$.

\begin{tabular}{cccccc}
\hline & $\begin{array}{c}\text { Leverage } \\
\text { Mean }\end{array}$ & $\begin{array}{c}\text { Leverage } \\
\text { Variance }\end{array}$ & $\begin{array}{c}\text { Value p.p. } \\
\text { Mean }\end{array}$ & $\begin{array}{c}\text { Tax } \\
\text { benefit }\end{array}$ & $\begin{array}{c}\text { Turnover } \\
\text { rate }\end{array}$ \\
\hline \multicolumn{5}{c}{ Innovation cost curvature } \\
\hline$\gamma=0.303$ & 23.51 & 1.93 & 0.47 & 3.53 & 0.81 \\
$\gamma=0.308$ & 25.06 & 2.25 & 0.46 & 3.76 & 0.81 \\
$\gamma=0.313$ & 26.03 & 2.52 & 0.44 & 3.90 & 0.80 \\
\hline
\end{tabular}

Innovation intensity: scale

\begin{tabular}{llllll}
\hline$\beta_{i}=20$ & 21.17 & 1.50 & 0.50 & 3.17 & 0.69 \\
$\beta_{i}=27$ & 25.06 & 2.25 & 0.46 & 3.76 & 0.81 \\
$\beta_{i}=34$ & 27.50 & 2.84 & 0.43 & 4.13 & 0.88 \\
\hline
\end{tabular}

Innovation quality: scale

\begin{tabular}{llllll}
\hline$\beta_{q}=45$ & 20.58 & 1.49 & 0.48 & 3.09 & 0.72 \\
$\beta_{q}=54$ & 25.06 & 2.25 & 0.46 & 3.76 & 0.81 \\
$\beta_{q}=63$ & 26.16 & 2.52 & 0.44 & 3.92 & 0.80 \\
\hline
\end{tabular}

Max \# new products per innovation

\begin{tabular}{llllll}
\hline$n=3$ & 25.06 & 2.25 & 0.46 & 3.76 & 0.81 \\
$n=4$ & 21.16 & 1.34 & 0.53 & 3.17 & 0.94 \\
$n=5$ & 15.95 & 0.64 & 0.58 & 2.39 & 0.91 \\
\hline \multicolumn{5}{c}{ Entry cost } \\
\hline$H=7.5$ & 23.16 & 1.97 & 0.47 & 3.47 & 0.82 \\
$H=8$ & 25.06 & 2.25 & 0.46 & 3.76 & 0.81 \\
$H=8.5$ & 26.24 & 2.40 & 0.45 & 3.94 & 0.78 \\
\hline \multicolumn{5}{c}{ Tax rate } \\
\hline$\pi=0.10$ & 19.23 & 1.39 & 0.47 \\
$\pi=0.20$ & 25.06 & 2.25 & 0.46 & 3.92 & 0.65 \\
$\pi=0.30$ & 33.06 & 3.26 & 0.43 & 0.81 \\
\hline \multicolumn{5}{c}{ Debt issuance cost } \\
\hline$\xi=0 \%$ & 29.56 & 3.10 & 0.45 & \\
$\xi=1.09 \%$ & 25.06 & 2.25 & 0.46 & 3.43 & 0.99 \\
$\xi=4.36 \%$ & 21.12 & 1.58 & 0.46 & 3.17 & 0.81 \\
\hline \multicolumn{7}{c}{}
\end{tabular}

Table 3: Comparative statics of selected moments. 


\section{R\&D investment and debt overhang}

To illustrate the trade-offs that firms face when determining their investment policy, we first show how they optimally choose their investment in innovation intensity $\lambda$ depending on their size, as captured by the number of product lines $p$ (the graph for innovation quality $\theta$ is similar). Figure 5 presents the optimal investment in innovation intensity $\lambda$ in four different cases: when firms are not allowed to hold any debt ('No debt'); when firms can issue debt ('Static debt'); in a 'Static debt first-best' case in which firms take the optimal debt policy from the baseline specification and choose their R\&D investment and default policy to maximize firm rather than equity value; when firms are allowed to dynamically adjust their capital structure ('Dynamic debt').

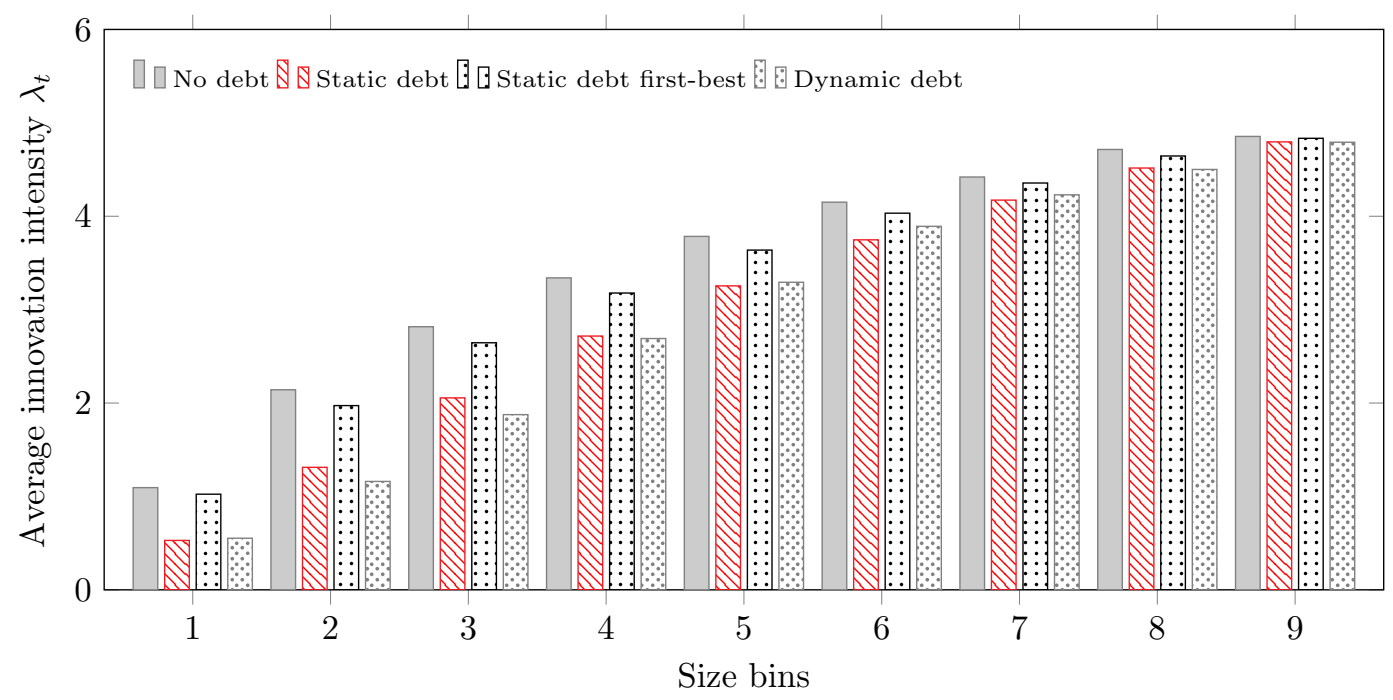

Figure 5: Debt overhang: optimal innovation intensity by size bins.

Figure 5 shows that debt reduces R\&D investment overall. In particular, when firms have few product lines and are small, debt overhang is more severe. As a result, firms invest less in both $R \& D$ intensity and quality. As expected, the average $R \& D$ investment is higher in the dynamic debt case than in the static debt case as firms initially issue less debt when they have the possibility to readjust their capital structure subsequently. In addition, the average R\&D investment is also higher in static debt first-best case and in the no debt specification than in the static debt case, reflecting the effects of agency conflicts on innovation policy. Overall, Figure 5 demonstrates that debt overhang is sizeable by showing that it also induces 
large distributional changes due to changes in firms' policies. It should be noted that Figure 5 is qualitatively similar to the empirical evidence on the number of patents presented in Figure 1, indicating that the model generates realistic predictions about firms' actual R\&D choices. We return to this issue in Section IV.
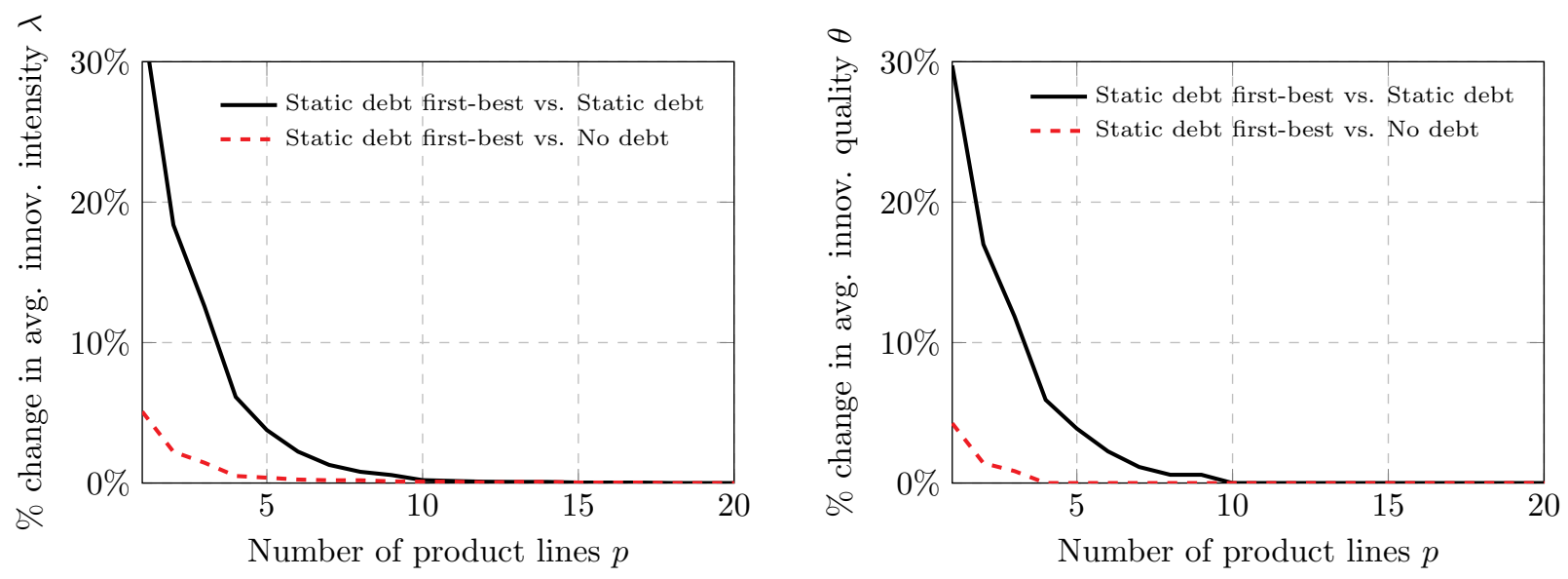

Figure 6: Changes in optimal R\&D investment policies by $p$ due to debt overhang and tax shield. In each case, the static debt first-best is computed using the rate of creative destruction from the no debt or static debt case, respectively, to isolate the effects of debt overhang and tax shield by controlling for distributional changes. The curves were nonparameterically smoothed.

To get a better sense of the effects of debt financing on R\&D investment, Figure 6 presents the changes in investment in innovation intensity $\lambda$ and quality $\theta$ as a function of the number of product lines $p$ in two cases. The first case, static debt first-best versus static debt, illustrates the effects of debt overhang. The second case, static debt first-best versus no debt, illustrates the effects of tax shield. The figure shows that in presence of debt firms not only spend less on R\&D investment overall, but also innovate less on each margin. The results convey two additional messages. First, the effects of debt overhang are substantial in the model. Depending on firm size $p$ and leverage, in the static debt first-best case firms invest up to $30 \%$ more in innovation intensity and quality compared to the baseline case. This distortion, that is solely due to debt, is especially strong for small firms. Second, the effects of tax shield are non-trivial as well: firms invest up to $3 \%$ more in innovation intensity and quality in the static debt first-best case as compared to the no debt case. The fact that these effects tend to become smaller as firm size $p$ increases is due to the fact that larger 
firms adopt lower leverage. Overall, the analysis indicates that debt has first-order effects on firms' R\&D investment policy.

\section{Financing policy and investment opportunities}
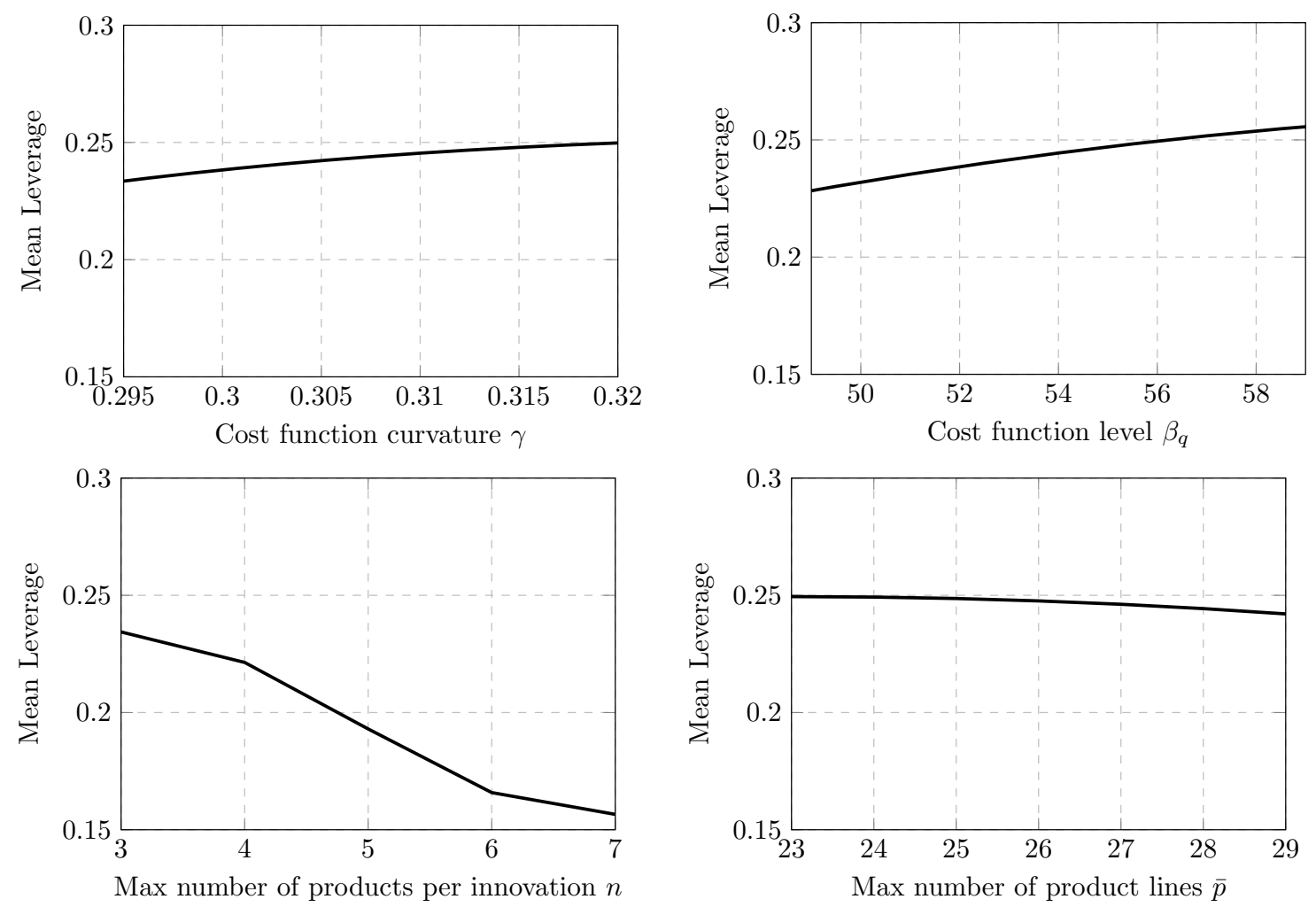

Figure 7: Investment opportunities and financing policy. The comparative statics were computed for the static debt case and smoothed using a second-order polynomial (in case of $\gamma$ and $\beta_{q}$ ).

Having documented how firms choose their optimal investment policy, we now illustrate how the trade-offs underlying their choice of leverage vary with their investment opportunity set. Figure 7 shows how firms' choice of leverage is affected by several key parameters describing their investment opportunities: the cost function curvature $\gamma$, the cost function level $\beta_{q}$, the maximum number of products per innovation $n$, and the maximum number of product lines $\bar{p}$.

In the model, higher R\&D costs decrease firms' incentives to innovate, feeding back into the trade-offs that determine their optimal leverage ratio. Higher R\&D costs lowers individual firms' incentives to innovate and therefore a smaller amount of their value comes from growth 
opportunities. In response, firms increase financial leverage. In equilibrium, lower individual levels of innovation lead to lower aggregate levels of innovation, and therefore a lower rate of creative destruction in the economy, which decrases the probability that a product becomes obsolete. The lower rate of creative destruction increases firms' incentives to issue debt.

Figure 7 also shows another important effect concerning the maximum number of product lines $\bar{p}$ and the maximum number of products per innovation $n$. When each innovation has the potential of creating more product lines, the potential costs of debt overhang are larger and firms issue less debt. This result is consistent with evidence in Smith and Watts (1992) and Barclay and Smith (1995) that firms with better growth opportunities adopt a lower leverage ratio. The effect of changing $\bar{p}$ on leverage is more muted. This is due to the fact that $\bar{p}$ has been chosen large enough so that the effects on firm policies of increasing it further would be limited.
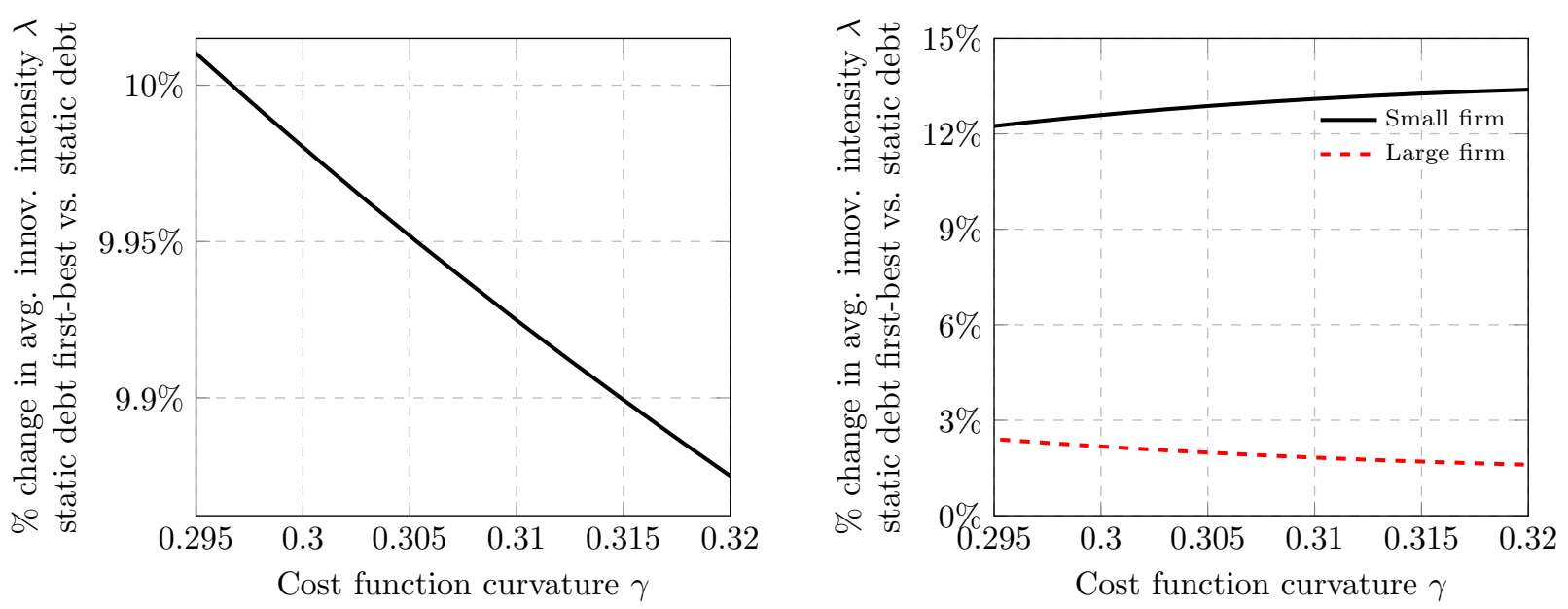

Figure 8: Investment opportunities and changes in optimal R\&D investment policies due to debt overhang. The comparative statics were computed for the static debt and first-best case and smoothed using a second-order polynomial. The 'small firm' line corresponds to a firm with $p=2$, while the 'large firm' line corresponds to a firm with $p=5$.

To quantify how debt overhang responds to investment opportunities, Figure 8 shows the differences in innovation intensity between the static debt first-best and the baseline specifications. The figure indicates that higher R\&D costs make the debt overhang problem less severe. For example, when the costs of performing R\&D are low, firms would have invested about $10 \%$ more in R\&D, but do not do so because of debt overhang, consistent 
with the evidence in Figure 5. Figure 8 shows that changing investment opportunities has direct and indirect effects on firms' R\&D investment policy by changing not only the cost of investing in R\&D but also the distortions in R\&D investment due to debt overhang. The figure also shows that the debt overhang problem is especially severe for small firms, and actually becomes more prominent when $\gamma$ increases, because then firms have higher leverage. Consistent with intuition conveyed by Figure 5, large firms are much less affected by debt overhang. Thus, while the effects of debt overhang are substantial for an average firm, they vary substantially across the firm size distribution.

\section{Industry equilibrium}

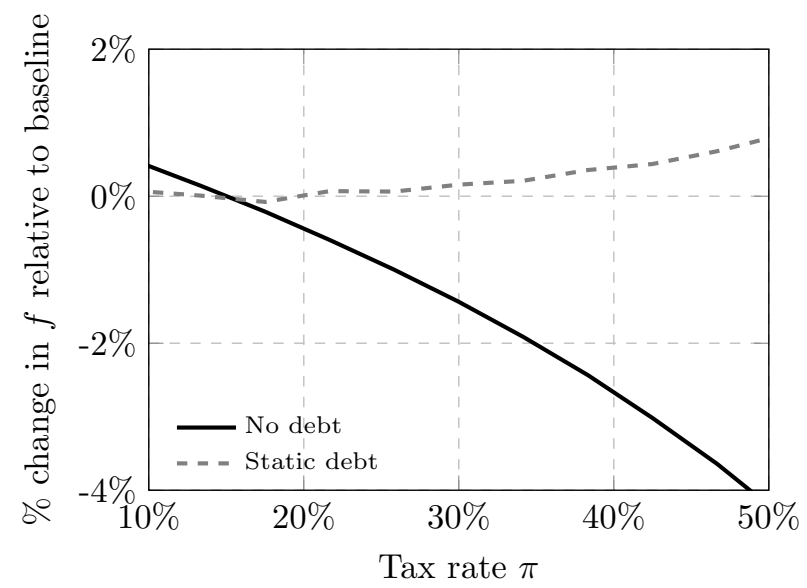

Figure 9: Debt and the rate of creative destruction. The comparative statics were computed for the static debt case.

Consider next equilibrium dynamics. Firms' policies affect the rate of creative destruction because they alter firm value, which influences the entry rate. As such, debt plays two distinctive roles in the model. On the one hand, debt financing leads to underinvestment (i.e. lower R\&D) by incumbents, in line with the effects of debt overhang presented earlier (Figure 5). On the other hand, debt leads to a higher rate of creative destruction because it increases firm value, which increases both the entry rate and the aggregate level of R\&D. ${ }^{7}$ This effect is illustrated in Figure 9 in which higher tax rate $\pi$-which is associated with

\footnotetext{
${ }^{7}$ It is important to realize that a single firm is infinitesimal and therefore cannot influence the rate of creative destruction by itself, but the actions of all firms can, for example if they all alter their policies when they get the possibility to issue debt.
} 
higher average leverage - results in a (slightly) higher rate of creative destruction $f$. The figure also shows that in the absence of debt, the equilibrium rate of creative destruction would have been not only lower, as suggested by Proposition 4, but would also decrease with the tax rate $\pi$, given that higher taxes lower firms' incentives to innovate, all else equal.
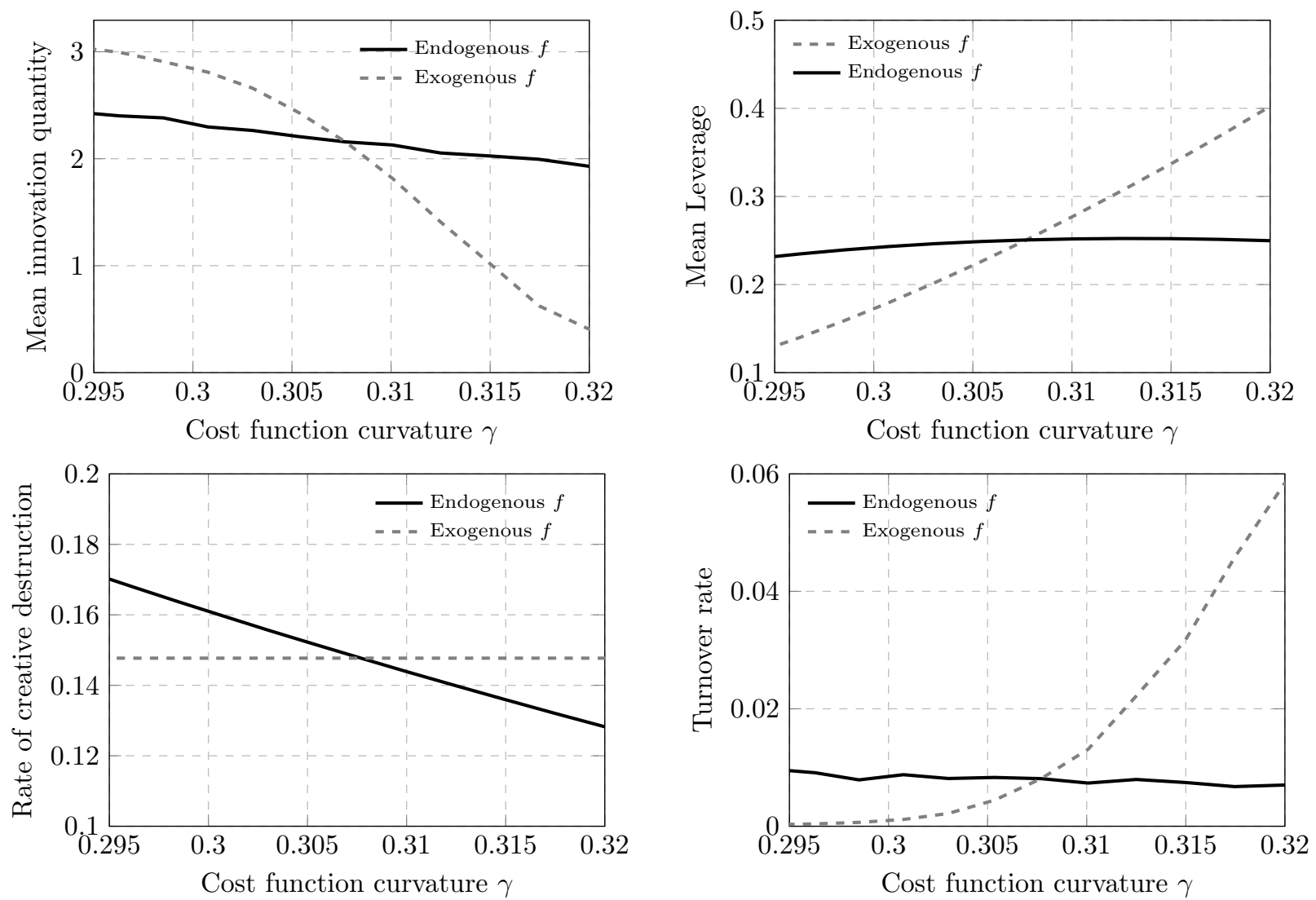

Figure 10: The effects of endogenous rate of creative destruction. The comparative statics were computed for the static debt case. The comparative statics for leverage were smoothed using a second-order polynomial.

In equilibrium, the industry rate of creative destruction and firms' capital structure decisions are jointly and endogenously determined. To better understand the underlying economic mechanism, Figure 10 shows how changing the cost of innovation $\gamma$ affects equilibrium quantities. The top left panel demonstrates that increasing the cost of innovation $\gamma$ lowers firms' investment in R\&D. Interestingly, when $f$ is fixed, the drop in $R \& D$ is much sharper as it does not incorporate the feedback from the industry. Because firms face worse growth opportunities when the cost of R\&D investment is high, much of their value is attributable to assets in place. As a result, they increase leverage, as shown by the top right panel of 
the figure. The effect is again weaker in industry equilibrium as the effects of $\gamma$ on $R \& D$ get muted. The drop in innovation quantity and the increase in leverage in turn feedback into the equilibrium rate of creative destruction, as illustrated in the bottom left panel of the figure. In equilibrium, the effect on innovation quantity is first order, leading to a negative relation between $\gamma$ and $f$. This decrease in the rate of creative destruction - and therefore the longer expected productive life of each product line - spurs innovation, partly offsetting the higher innovation costs. Lastly, as illustrated by the bottom right panel, these mechanisms translate to a lower turnover rate as $\gamma$ increases, because the decrease in the rate of creative destruction compensates for the lower levels of innovation. By contrast, with $f$ fixed, the sharp increase in leverage leads to a sharp increase in the turnover rate.
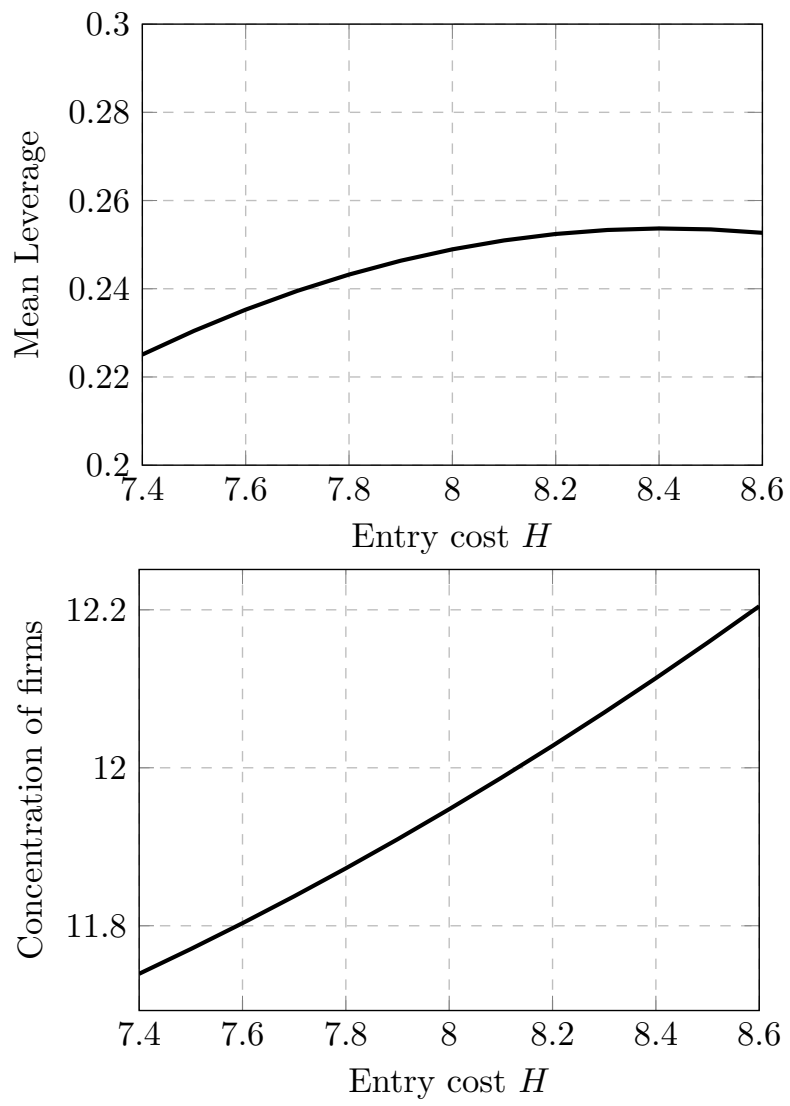

Figure 11: Leverage and industry concentration. The comparative statics were computed for the baseline static debt case and smoothed using a second-order polynomial. The measure of concentration is the inverse of the expected mass of firms.

It is also worth mentioning that higher entry cost $H$ results in higher leverage and higher concentration in the industry, as shown in Fig 11. The model is therefore able to replicate 
the result in MacKay and Phillips (2005) that firms in more concentrated industries tend to adopt higher leverage ratios.

\section{Size distribution}

Debt also has important implications for the size distribution of firms. To illustrate these implications, Figure 12 presents this distribution for the no debt, static debt, and dynamic debt cases. The figure shows that the distribution is positively skewed when firms are allowed to issue debt, which can be attributed to debt overhang changing firms' incentives to innovate and to the higher turnover rate. The results imply that the option to restructure debt in the future mitigates the effect of debt on the exit rate, as the size distribution in the dynamic debt case is below that for the static debt case when $p$ is smaller and above when $p$ is larger. Figure 12 demonstrates that debt has a first-order effects on the distribution of firms, which validates the results in the histogram of Figure 5.

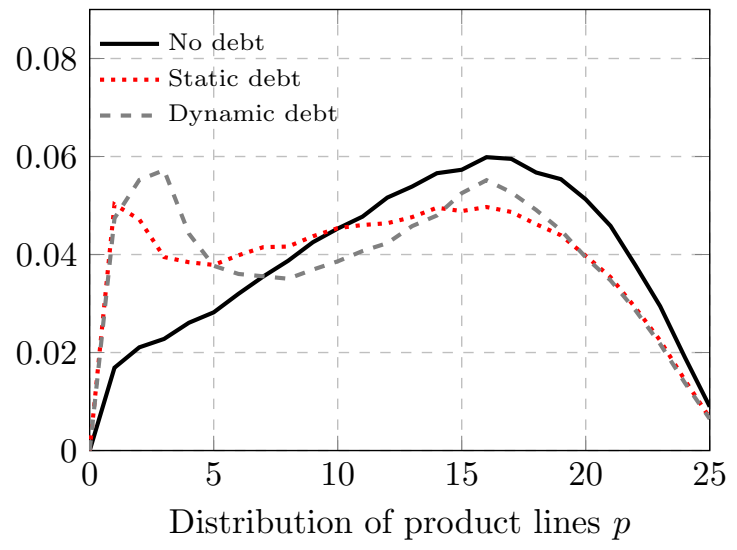

Figure 12: Distribution of the number of products $p$. The figure shows the distribution of the number of products $p$ in the 'No debt' (solid) and 'static debt' (dotted) cases.

The importance of the change in distribution varies with firm characteristics. Figure 13 shows how the key parameters of the model affect firm size distribution: the maximum number of products per innovation $n$, the cost function curvature $\gamma$, the tax rate $\pi$, and the entry cost $H$. The figure shows that $n$ and $H$ have similar effects on firm size distribution. However, the underlying economic mechanism is different. Table 2 indicates that larger $H$ decreases the turnover rate, while the effect of increasing $n$ is the opposite. In particular, the size distribution is shifted to the left when firms can generate fewer products per innovation, 
which effectively lowers their growth rates, and when there are more entrants. The tax rate $\pi$ is also an important determinant of the size distribution, since a higher tax rate limits the benefits of a larger cash flow and thus firms' investment in innovation, resulting in smaller firms, on average. Finally, the effects of changing firms' innovation cost structure on the size distribution are less important, but affect the shape of the distribution for two reasons. Higher innovation costs shift the size distribution to the left, because they effectively lower firms' growth rates, and they also lower the rate of creative destruction, which in turn affects the turnover rate.
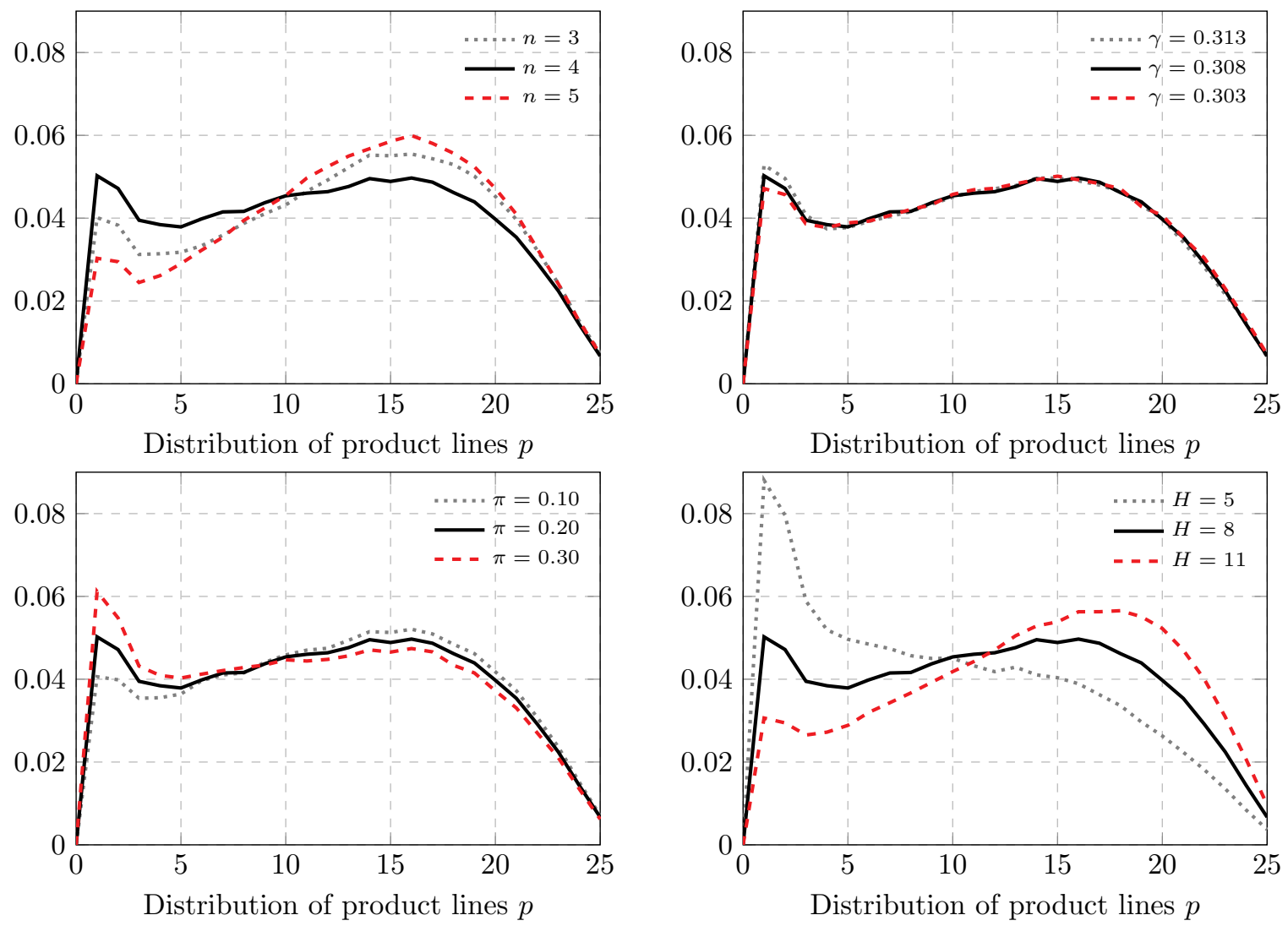

Figure 13: Firm characteristics and distribution of the number of products $p$. The figure shows the distribution of the number of products $p$ in the baseline static debt model for different firm characteristics: the maximum number of product per innovation $n$, the cost function curvature $\gamma$, the tax rate $\pi$, and the entry cost $H$. 


\section{General Equilibrium}

This section closes the model in general equilibrium to endogenize the growth rate, wages, and the interest rate in the economy. The general equilibrium setup builds on Klette and Kortum (2004). We study a stationary equilibrium with a balanced growth path. This subsection describes the most important details of the general equilibrium framework, see Appendix D for a more detailed and formal description.

\section{A Model Description}

There is a unit mass of differentiated goods in the economy, which are indexed by $i \in[0,1]$, and a representative household with logarithmic preferences. As in Klette and Kortum (2004) or Aghion, Bloom, Blundell, Griffith, and Howitt (2005), the aggregate consumption $C_{t}$ follows from a logarithmic consumption aggregator

$$
\ln \left(C_{t}\right)=\int_{0}^{1} \ln \left(c_{t}^{i}\right) d i
$$

where $c_{t}^{i}$ the amount of good $i$ consumed by the representative household at time $t$. The logarithm of consumption $\ln \left(C_{t}\right)$ is used as the numeraire in this economy.

The representative household inelastically supplies $L_{S}>1$ units of labor and receives a wage $w$ for each unit of labor. All costs in the model come in the form of labor costs, and therefore aggregate production equals aggregate consumption.

Incumbents use labor and installed product lines to produce goods. An improvement in the production technology increases the amount of the consumption good that one unit of labor produces. As in the industry equilibrium framework, there is a leading producer for each type of product. The production technology of good $i$ 's leading producer is $q_{t}^{i}$ and determines the number of products that one unit of labor produces. A firm that innovates on product $i$ improves the production technology and becomes the leading producer. We assume that when an innovation arrives at time $t$, the production technology goes from $q_{t^{-}}^{i}$ to $q_{t}^{i}=(1+\delta) q_{t^{-}}^{i}$ with $\delta>0$. A firm that owns the leading production technology for product 
$i$ is a monopolist for that good and can choose to supply or not to supply. If the firm supplies the good then it uses one unit of labor to generate $q_{t}^{i}$ units of the product. If it does not supply the good then output and revenues are zero.

The firm can also invest in R\&D. As in Klette and Kortum (2004), R\&D costs come in the form of labor costs. R\&D cost are the wage rate multiplied by the number of hours spend on R\&D. Therefore, for incumbents and entrants their R\&D costs are

$$
\begin{aligned}
q(p, \lambda, \theta) & =w * \tilde{q}(p, \lambda, \theta), \\
q_{e}(\lambda, \theta) & =w * \tilde{q}_{e}(\lambda, \theta) .
\end{aligned}
$$

In the industry equilibrium model, entrants pay a fixed entry cost $H$ to become an entrant. In our general equilibrium model, these fixed costs are replaced by labor costs. An entrepreneur can hire one unit of labor, which costs him $w$, and that generates an idea with Poisson intensity $h$. Once the entrepeneur has generated this idea he can become an entrant. This implies that the free entry condition becomes $E^{e}(f)=\frac{w}{h}$, since in equilibrium the cost and benefits should equate for an entrepreneur

$$
E^{e}(f) h=w .
$$

Finally, we allow the firm to have static debt (or no debt) and assume there are no debt issuance $\operatorname{cost} \xi=0$ and default cost $\alpha=0$ to ensure that all costs come in the form of labor costs.

Under these assumptions, the marginal cost of production is $\frac{w}{q_{t}^{i}}$. The inverse demand curve determines the price and therefore the profits on product $i$ are

$$
\pi_{t}^{i}=q_{t}^{i}\left(\frac{1}{q_{t}^{i}}-\frac{w}{q_{t}^{i}}\right)=1-w
$$

The profits of a product line is independent of the production technology $q_{t}^{i}$, which allows us to use the setup and results from previous sections to develop a general equilibrium framework. A firm is the leading producer of $P_{t}$ products, each of which generates a profits flow of $(1-w)$.

In equilibrium, the growth rate $g$, wages $w$, and the interest rate $r$ are determined by 
market clearing in the product and labor market. Consumption grows at the rate

$$
d \ln \left(C_{t}\right)=d \int_{0}^{1} \ln \left(c_{t}^{i}\right) d i=\ln (1+\delta) f d t=g d t
$$

where $f$ is the rate of creative destruction in the economy, which is caused by innovations by incumbents and entrants.

\section{B Model Analysis}

To be completed.

\section{Conclusion}

This article develops a Schumpeterian growth model of financing and innovation decisions to study the relation between debt financing, innovation and growth. In the model, each firm's R\&D policy influences its risk profile, which affects the firm's capital structure decisions. Furthermore, a leveraged firm's investment policy can be altered by debt overhang. Thus, each firm determines its optimal capital structure by trading off the tax benefits of debt against default costs and distortions in R\&D investment due to debt financing. We embed the individual firm model into a Schumpeterian industry equilibrium that endogenizes the rate of creative destruction, and derive a steady state equilibrium in which innovating firms introduce new products that replace existing ones, and new entrants replace exiting incumbents. The industry equilibrium results in firms' individual R\&D and capital structure decisions affecting the aggregate level of creative destruction, which feeds back to their individual policy choices.

We show that financing and investment decisions are intertwined at the individual-firm level, with high levels of debt leading to underinvestment in R\&D due to debt overhang. As the R\&D policy can influence the probability of default, and are themselves influenced by the rate of creative destruction, firms' capital structure decisions are affected by their innovation policy. Importantly, we demonstrate that debt financing stimulates innovation and creative destruction at the aggregate level. Overall, we illustrate that conclusions reached in a singlefirm model can vary substantially from those resulting from a Schumpeterian growth model. 


\section{References}

Acemoglu, Daron, 2009, Introduction to Modern Economic Growth (Princeton University Press).

Acemoglu, Daron, Ufuk Akcigit, Harun Alp, Nicholas Bloom, and William Kerr, 2018, Innovation, reallocation and growth, American Economic Review 108, 3450-3491.

Admati, Anat R., Peter M. Demarzo, Martin F. Hellwig, and Paul Pfleiderer, 2018, The leverage ratchet effect, The Journal of Finance 73, 145-198.

Aghion, Philippe, Ufuk Akcigit, and Peter Howitt, 2014, What do we learn from Schumpeterian growth theory?, volume 2 (Elsevier B.V.).

Aghion, Philippe, Nick Bloom, Richard Blundell, Rachel Griffith, and Peter Howitt, 2005, Competition and Innovation: an Inverted-U Relationship, The Quarterly Journal of Economics 120, 701-728.

Akcigit, Ufuk, and William R. Kerr, 2018, Growth through heterogeneous innovations, Journal of Political Economy 126, 1374-1443.

Altinkilic, Oya, and Robert S Hansen, 2000, Are there economies of scale in underwriting fees? Evidence of rising external financing costs, Review of Financial Studies 13, 191-218.

Barclay, Michael J, and Clifford W Smith, 1995, The maturity structure of corporate debt, The Journal of Finance 50, 609-631.

Bena, Jan, Lorenzo Garlappi, and Patrick Grüning, 2015, Heterogeneous innovations, firm creation and destruction, and asset prices, The Review of Asset Pricing Studies 1, 46-87.

Chava, Sudheer, and Michael R Roberts, 2008, How does financing impact investment? The role of debt covenants, The Journal of Finance 63, 2085-2121.

Corbae, Dean, and Pablo D D'Erasmo, 2017, Reorganization or liquidation: bankruptcy choice and firm dynamics, National Bureau of Economic Research. 1-65.

Davis, Jesse, Adair Morse, and Xinxin Wang, 2018, The leveraging of silicon valley . 
DeMarzo, Peter, and Zhiguo He, 2018, Leverage dynamics without commitment .

Doidge, Craig, Kathleen M Kahle, Andrew G. Karolyi, and René M Stulz, 2018, Eclipse of the public corporation or eclipse of the public markets?, Journal of Applied Corporate Finance 30, 8-16.

Duffie, Darrell, and David Lando, 2001, Term structures of credit spreads with incomplete accounting information, Econometrica 69, 633-664.

Favara, Giovanni, Erwan Morellec, Enrique Schroth, and Philip Valta, 2017, Debt enforcement, investment, and risk taking across countries, Journal of Financial Economics 123, $22-41$.

Fischer, Edwin O., Robert Heinkel, and Josef Zechner, 1989, Dynamic capital structure choice: Theory and tests, The Journal of Finance 44, 19-40.

Fries, Steven, Marcus Miller, and William Perraudin, 1997, Debt in industry equilibrium, Review of Financial Studies 10, 39-67.

Garleanu, Nicolae, and Stavros Panageas, 2018, Finance in a time of disruptive growth .

Garleanu, Nicolae, Stavros Panageas, and Jianfeng Yu, 2012, Technological growth and asset pricing, Journal of Finance 67, 1265-1292.

Gilson, Stuart C, 1997, Transactions costs and capital structure choice: Evidence from financially distressed firms, The Journal of Finance 52, 161-196.

Giroud, Xavier, Holger M. Mueller, Alex Stomper, and Arne Westerkamp, 2012, Snow and leverage, Review of Financial Studies 25, 680-710.

Glover, Brent, 2016, The expected cost of default, Journal of Financial Economics 119, 284-299.

Goldstein, Robert, Nengjiu Ju, and Hayne Leland, 2001, An EBIT-based model of dynamic capital structure, The Journal of Business 74, 483-512. 
Graham, John R., 1996, Proxies for the corporate marginal tax rate, Journal of Financial Economics 42, 187-221.

Graham, John R., Mark T. Leary, and Michael R. Roberts, 2015, A century of capital structure: The leveraging of corporate America, Journal of Financial Economics 118, 658-683.

Hochberg, Yael V., Carlos J. Serrano, and Rosemarie H. Ziedonis, 2017, Patent collateral, investor commitment, and the market for venture lending, Journal of Financial Economics

Hugonnier, Julien, Semyon Malamud, and Erwan Morellec, 2015, Credit market frictions and capital structure dynamics, Journal of Economic Theory 157, 1130-1158.

Ibrahim, Darian M., 2010, Debt as venture capital, University of Illinois Law Review $1169-1210$.

Klette, Tor Jakob, and Samuel Kortum, 2004, Innovating firms and aggregate innovation, Journal of Political Economy 112, 986-1018.

Kogan, Leonid, Dimitris Papanikolaou, Amit Seru, and Noah Stoffman, 2017, Technological innovation, resource allocation, and growth, Quarterly Journal of Economics 132, 665-712.

Kogan, Leonid, Dimitris Papanikolaou, and Noah Stoffman, 2018, Left behind: creative destruction, inequality, and the stock market, Journal of Political Economy .

Korteweg, Arthur, 2010, The net benefits to leverage, The Journal of Finance 65, 2137-2170.

Kung, Howard, and Lukas Schmid, 2015, Innovation, growth, and asset prices, Journal of Finance 70, 1001-1037.

Leahy, John V., 1993, Investment in competitive equilibrium: The optimality of myopic behavior, The Quarterly Journal of Economics 108, 1105-1133.

Leland, H E, 1994, Corporate debt value, bond covenants, and optimal capital structure, The Journal of Finance 49, 1213-1252. 
Leland, Hayne E, 1998, Agency costs, risk management, and capital structure, The Journal of Finance 53, 1213-1243.

Lentz, Rasmus, and Dale T. Mortensen, 2008, An empirical model of growth through product innovation, Econometrica 76, 1317-1373.

MacKay, Peter, and Gordon M. Phillips, 2005, How does industry affect firm financial structure?, Review of Financial Studies 18, 1433-1466.

Malamud, Semyon, and Francesca Zucchi, 2017, Liquidity, innovation, and endogenous growth, Journal of Financial Economics .

Manso, Gustavo, 2008, Investment reversibility and agency cost of debt, Econometrica 76 , $437-442$.

Miao, Jianjun, 2005, Optimal capital structure and industry dynamics, The Journal of Finance 60, 2621-2659.

Modigliani, F, and M H Miller, 1958, The cost of capital, corporation finance and the theory of investment, American Economic Review 48, 261-297.

Morellec, E, B Nikolov, and N Schürhoff, 2012, Corporate governance and capital structure dynamics, The Journal of Finance 67, 803-848.

Morellec, Erwan, Boris Nikolov, and Norman Schürhoff, 2017, Agency Conflicts Around the World, Review of Financial Studies .

Myers, S C, 1977, Determinants of corporate borrowing, Journal of Financial Economics 5, $147-175$.

Robb, Alicia M., and David T. Robinson, 2014, The capital structure decisions of new firms, Review of Financial Studies 27, 153-179.

Romer, Paul M, 1990, Endogenous technological change, Journal of Political Economy 98, $71-102$. 
Smith, Clifford W., and Ross L. Watts, 1992, The investment opportunity set and corporate financing, dividend, and compensation policies, Journal of Financial Economics 32, 263-292.

Stokey, Nancy L., Robert E. Lucas, and Edward C Prescott, 1989, Recursive methods in economic dynamics (Harvard University Press).

Strebulaev, Ilya A, 2007, Do tests of capital structure theory mean what they say?, The Journal of Finance 62, 1747-1787.

van Binsbergen, Jules H, John R Graham, and Jie Yang, 2010, The cost of debt, The Journal of Finance 65, 2089-2136.

Zhdanov, Alexei, 2007, Competitive equilibrium with debt, Journal of Financial and Ouantitative Analysis 42, 709-734. 


\section{Appendix}

The appendix consists of four parts. We solve the static debt case (Theorem 1 and Proposition 1) in Section A. In Section B, we embed this static debt model into an industry equilibrium in the second part (Theorem 2 and Proposition 2). In Section C, we solve the model with refinancing (Theorem 4, Theorem 3, and Proposition 5). In Section D, we close the model in general equilibirum.

\section{A Debt Financing}

First, we establish the individual firm results (Theorem 1) and intermediate results that show that the equity value is continuous and decreasing in $f$ and $c$ (Lemma 1). Finally, we proof the comparative statics results (Proposition 1).

In the static debt model an incumbent's coupon is constant. Therefore, we write the equity value as

$$
E(p)=E(p, c)
$$

and use it when it does not lead to confusion. Furthermore, the equity value indirectly depends on the parameters $f$ and $c$. When necessary, we make this dependence explicit by writing $E(p \mid f, c)$.

Theorem 1 (Equity Value). A unique solution to the equity value (2) exists. Equity value is non-decreasing in $p$ and therefore the optimal default strategy is a barrier default strategy $\tau_{D}=\inf \left\{t>0 \mid P_{t} \leq p_{D}\right\}$. If the optimal level of $R \& D$ is interior $((\lambda, \theta) \in(0, \bar{\lambda}) \times(0,1))$, it solves

$$
\begin{aligned}
\mathbb{E}^{\theta}[E(\min \{p+x, \bar{p}\}, c)]-E(p, c) & =(1-\pi) \frac{\partial q(p, \lambda, \theta)}{\partial \lambda}, \\
\lambda \frac{\partial \mathbb{E}^{\theta}[E(\min \{p+x, \bar{p}\}, c)]}{\partial \theta} & =(1-\pi) \frac{\partial q(p, \lambda, \theta)}{\partial \theta} .
\end{aligned}
$$

Proof. The proof has several steps. First, we establish existence of the equity value after which we show that it is increasing in the number of product lines $p$. Finally, we derive the first-order conditions that the internal optimal level of R\&D satisfies.

1. Equation (3) shows that the equity value for $p \in\{1, \ldots, \bar{p}\}$ can be rewritten as

$$
\begin{aligned}
E(p)=\sup _{\theta, \lambda, \tau_{D}}\{ & \mathbb{E}_{p}\left[\int_{0}^{\tau_{D}} e^{-(r+\lambda+p f) t}(1-\pi)(p-c-q(p, \lambda, \theta)) d t\right] \\
& \left.+\mathbb{E}_{p}\left[\int_{0}^{\tau_{D}} e^{-(r+\lambda+p f) t}\left(\lambda \mathbb{E}^{\theta}[E(\min \{p+x, \bar{p}\})]+p f E(p-1)\right) d t\right]\right\}
\end{aligned}
$$


with $E(0)=0$. Define $\mathcal{M}(E)$ as the mapping

$$
\begin{aligned}
\mathcal{M}(E)=\sup _{\theta, \lambda, \tau_{D}}\{ & \mathbb{E}_{p}\left[\int_{0}^{\tau_{D}} e^{-(r+\lambda+p f) t}(1-\pi)(p-c-q(p, \lambda, \theta)) d t\right] \\
& \left.+\mathbb{E}_{p}\left[\int_{0}^{\tau_{D}} e^{-(r+\lambda+p f) t}\left(\lambda \mathbb{E}^{\theta}[E(\min \{p+x, \bar{p}\})]+p f E(p-1)\right) d t\right]\right\} .
\end{aligned}
$$

Any fixed point of this mapping is bounded from above by $\bar{p} / r$ and from below by zero. Furthermore, the mapping is monotone in $E$ and finally,

$$
\begin{aligned}
\mathcal{M}(E+L)=\sup _{\theta, \lambda, \tau_{D}}\left\{\mathbb{E}_{p}\left[\int_{0}^{\tau_{D}} e^{-(r+\lambda+p f) t}(1-\pi)(p-c-q(p, \lambda, \theta)) d t\right]\right. & \\
& +\mathbb{E}_{p}\left[\int_{0}^{\tau_{D}} e^{-(r+\lambda+p f) t} \lambda \mathbb{E}^{\theta}([E(\min \{p+x, \bar{p}\})]+L) d t\right] \\
& \left.+\mathbb{E}_{p}\left[\int_{0}^{\tau_{D}} e^{-(r+\lambda+p f) t} p f(E(p-1)+L) d t\right]\right\}, \\
\mathcal{M}(E+L) \leq \mathcal{L}(E) & +\frac{\bar{\lambda}+\bar{p} f}{r+\bar{\lambda}+\bar{p} f} L,
\end{aligned}
$$

because $\lambda \leq \bar{\lambda}$ by assumption. Therefore, the mapping $\mathcal{M}(E)$ satisfies Blackwell's sufficient conditions for a contraction, see Theorem 3.3 on page 54 in Stokey, Lucas, and Prescott (1989), and it is a contraction mapping, which implies that a fixed point exists and is unique. The equity value is the fixed point of this mapping.

2. The next step is to show that the equity value is non-decreasing in $p$. If shareholders own $p+1$ product lines they can always separate one of the product lines from the firm and collect the cash flows from this separated product line until either this product line fails, the firms number of product lines reaches $\bar{p}$, the firm defaults $\tau_{D}$, or the number of product lines reaches zero, while continuing to run the firm as if it has only $p$ product lines. In this case the equity value would be,

$$
E(p)+\mathbb{E}_{p}\left[\int_{0}^{\tau_{D}(p) \wedge \tau_{0}(p) \wedge \tau_{\bar{p}}(p)} e^{-(r+\lambda) t}(1-\pi)\left(1-q\left(P_{t}+1, \lambda_{t}, \theta_{t}\right)+q\left(P_{t}, \lambda_{t}, \theta_{t}\right)\right) d t\right] \leq E(p+1),
$$

where $\tau_{D}(p)$ is the optimal default time of a firm that starts with $p$ product lines, $\tau_{0}(p)$ is the first time the firm has zero product lines if it starts with $p$ product lines, and $\tau_{\bar{p}}$ is the first time a firm with $p$ product lines would have $\bar{p}$ product lines. The inequality follows from the fact that this product line separation strategy is suboptimal for a $p+1$ product line firm. The condition on the issuance cost function ensure that the second term on the left-hand side is non-negative. This shows that the equity value $E(p)$ is non-decreasing in $p$. It also implies that a barrier default strategy is the optimal default strategy. 
3. Finally, the (internal) optimal levels of $R \& D$ should satisfy the first-order conditions that follow from equation (3).

Lemma 1. The equity value $E(p \mid f, c)$ is continuous and non-increasing in $f$ and $c$. If $E(p \mid f, c)>0$ then the equity value is decreasing in $f$ and $c$.

Proof. We first show the result for $f$ and then for $c$.

1. Fix an $f_{2}<f_{1}$. Let $P_{t}^{1}$ be the number of product lines that a firm that faces rate of creative destruction $f_{1}$ has. We know that

$$
E\left(p \mid f_{1}\right)=\mathbb{E}_{p}\left[\int_{0}^{\tau_{D}^{1} \wedge \tau_{0}^{1}} e^{-r t}(1-\pi)\left(P_{t}^{1}-c-q\left(P_{t}^{1}, \lambda_{t}^{1}, \theta_{t}^{1}\right)\right) d t\right],
$$

where $\left\{\lambda_{t}^{1}, \theta_{t}^{1}\right\}, \tau_{D}^{1}$ are shareholders optimal strategy given $f_{1}$. The dynamics of $P_{t}^{1}$ are

$$
d P_{t}^{1}=d I_{t}^{1}-d O_{t}^{1}=\max \left(Y_{t}^{1}, \bar{p}-P_{t^{-}}^{1}\right) d N_{t}^{1}-d O_{t}^{1}
$$

with

$$
\mathbb{E}\left[d P_{t}^{1}\right]=\lambda_{t}^{1} \mathbb{E}^{\theta_{t}^{1}}\left[\max \left(Y_{t}^{1}, \bar{p}-P_{t^{-}}^{1}\right)\right] d t-f_{1} P_{t^{-}}^{1} d t .
$$

2. Define $\tilde{P}_{t}^{2}$ as,

$$
d \tilde{P}_{t}^{2}=d \tilde{I}_{t}^{1}-X_{t} d O_{t}^{1}-d H_{t},
$$

where

$$
\begin{aligned}
\tilde{I}_{t}^{1} & =\max \left(Y_{t}^{1}, \bar{p}-\tilde{P}_{t^{-}}^{2}\right) d N_{t}^{1}, \\
X_{t} & \sim \operatorname{Bin}\left(1, \frac{f_{2}}{f_{1}}\right), \\
H_{t} & \sim \operatorname{Poisson}\left(f_{2}\left(\tilde{P}_{t}^{2}-P_{t}^{1}\right)\right) .
\end{aligned}
$$

The construction of $X_{t}$ and $H_{t}$ implies that,

$$
\mathbb{E}_{t}\left[d \tilde{O}_{t}^{1} X_{t}-d H_{t}\right]=\frac{f_{2}}{f_{1}} f_{1} P_{t}^{1} d t-f_{2}\left(\tilde{P}_{t}^{2}-P_{t^{-}}^{1}\right) d t=f_{2} \tilde{P}_{t^{-}}^{2} d t .
$$

These dynamics for $\tilde{P}_{t}^{2}$ imply that it evolves according to the R\&D strategy $\left\{\lambda_{t}^{1}, \theta_{t}^{1}\right\}$ given a failure intensity of $f_{2}$. The construction $\tilde{P}_{t}^{2}$ ensures that

$$
P_{t}^{1} \leq \tilde{P}_{t}^{2}
$$

If $\tilde{P}_{t^{-}}^{2}=P_{t^{-}}^{1}$ then innovation dynamics are the same $d I_{t}^{1}=d \tilde{I}_{t}^{2}$. Furthermore, product line failure is higher for $P_{t^{-}}^{1}$ since $f_{2} / f_{1}<1$ and if a product line fails for $\tilde{P}_{t^{-}}^{2}$ then it 
fails for $P_{t^{-}}^{1}$. Therefore, if $\tilde{P}_{t^{-}}^{2}=P_{t^{-}}^{1}$ then $\tilde{P}_{t}^{2} \geq P_{t}^{1}$. If $\tilde{P}_{t^{-}}^{2}>P_{t^{-}}^{1}$ then product line failure can never imply $\tilde{P}_{t}^{2}<P_{t}^{1}$ since product lines drop by only one. Furthermore, by construction innovation happens at the same time and the number of product lines created for both is either $Y_{t}$ or $\bar{p}$ is reached. This implies that if at time $t$ product lines are created and $\tilde{P}_{t^{-}}^{2}>P_{t^{-}}^{1}$ then $\tilde{P}_{t}^{2}=\min \left(\tilde{P}_{t^{-}}^{2}+Y_{t}, \bar{p}\right) \geq \min \left(P_{t^{-}}^{1}+Y_{t}, \bar{p}\right)=P_{t}^{1}$. Therefore, if $\tilde{P}_{t^{-}}^{2}>P_{t^{-}}^{1}$ then $\tilde{P}_{t}^{2} \geq P_{t}^{1}$.

3. Given the assumptions on the cost function the equity value satisfies

$$
\begin{aligned}
E\left(p \mid f_{1}\right) & =\mathbb{E}_{p}\left[\int_{0}^{\tau_{D}^{1} \wedge \tau_{0}^{1}} e^{-r t}(1-\pi)\left(P_{t}^{1}-c-q\left(P_{t}^{1}, \lambda_{t}^{1}, \theta_{t}^{1}\right)\right) d t\right] \\
& \leq \mathbb{E}_{p}\left[\int_{0}^{\tau_{D}^{1} \wedge \tau_{0}^{1}} e^{-r t}(1-\pi)\left(\tilde{P}_{t}^{2}-c-q\left(\tilde{P}_{t}^{2}, \lambda_{t}^{1}, \theta_{t}^{1}\right)\right) d t\right] \\
& \leq E\left(p \mid f_{2}\right) .
\end{aligned}
$$

If the equity value is positive then $\tau_{D}^{1} \wedge \tau_{0}^{1}>0$ and the second inequality becomes a strict inequality. This shows that $E(p \mid f)$ is non-increasing in $f$ and strictly decreasing in $f$ when $E(p \mid f)>0$.

4. The next step is showing that the equity value is continuous in $f$. The mapping $\mathcal{M}(E \mid f)$ is continuous in $f$. Therefore, for every $\epsilon>0$ there exists a $\delta>0$ such that for $f^{\prime} \in(f-\delta, f+\delta)$,

$$
\left\|\mathcal{M}\left(E(p \mid f) \mid f^{\prime}\right)-E(p \mid f)\right\|=\left\|\mathcal{M}\left(E(p \mid f) \mid f^{\prime}\right)-\mathcal{M}(E(p \mid f) \mid f)\right\|<\epsilon .
$$

Fix one such $\epsilon$. Applying the mapping $\mathcal{M}$ again leads to,

$$
\left\|\mathcal{M}^{2}\left(E(p \mid f) \mid f^{\prime}\right)-\mathcal{M}\left(E(p \mid f) \mid f^{\prime}\right)\right\|<U\left\|\mathcal{M}\left(E(p \mid f) \mid f^{\prime}\right)-E(p \mid f)\right\|<U \epsilon .
$$

where

$$
U=\frac{\bar{\lambda}+\bar{p} f^{\prime}}{r+\bar{\lambda}+\bar{p} f^{\prime}} .
$$

This process can be repeated (where $\mathcal{M}^{m}(E \mid f)$ means applying the mapping $\mathcal{M}(\cdot \mid f)$ $m$ times to $E$ ) and leads to

$$
\left\|\mathcal{M}^{m+1}\left(E(p \mid f) \mid f^{\prime}\right)-\mathcal{M}^{m}\left(E(p \mid f) \mid f^{\prime}\right)\right\|<U^{m} \epsilon .
$$


Therefore, the distance between $E(p \mid f)$ and $E\left(p \mid f^{\prime}\right)$ is bounded by

$$
\begin{aligned}
\left\|E(p \mid f)-E\left(p \mid f^{\prime}\right)\right\| & =\left\|E(p \mid f)-\mathcal{M}^{\infty}\left(E(p \mid f) \mid f^{\prime}\right)\right\| \\
& \leq \sum_{i=0}^{\infty}\left\|\mathcal{M}^{i+1}\left(E(p \mid f) \mid f^{\prime}\right)-\mathcal{M}^{i}\left(E(p \mid f) \mid f^{\prime}\right)\right\| \\
& <\epsilon \sum_{i=0}^{\infty} U^{i} \\
& =\epsilon \frac{1}{1-U} \\
& =\epsilon \frac{r+\bar{\lambda}+\bar{p}\left(f+\left(f^{\prime}-f\right)\right)}{r} \\
& \leq \epsilon \frac{r+\bar{\lambda}+\bar{p}(f+\delta)}{r} .
\end{aligned}
$$

Set $\tilde{\delta}=\min \{\delta, 1\}$ and

$$
\tilde{\epsilon}=\epsilon \frac{r+\bar{\lambda}+\bar{p}(f+1)}{r} .
$$

This implies that for every $\tilde{\epsilon}>0$ there exists a $\tilde{\delta}>0$ such that for $f^{\prime} \in(f-\tilde{\delta}, f+\tilde{\delta})$,

$$
\left\|E(p \mid f)-E\left(p \mid f^{\prime}\right)\right\|<\tilde{\epsilon}
$$

Therefore, $E(p \mid f)$ is continuous in $f$. The same argument shows that $E(p \mid c)$ is continuous in $c$.

5. The final step is showing that the equity value is non-increasing in $c$ and decreasing if $E(p \mid c)>0$. The mapping $\mathcal{M}(E \mid c)$ is non-increasing in $c$ and non-decreasing in $E$. Therefore, for a $c<c^{\prime}$ we have that,

$$
\begin{aligned}
E(p \mid c) & =\mathcal{M}(E(p \mid c) \mid c) \\
& \geq \mathcal{M}\left(E(p \mid c) \mid c^{\prime}\right) \\
& \geq \mathcal{M}^{2}\left(E(p \mid c) \mid c^{\prime}\right) \\
& \geq \mathcal{M}^{n>2}\left(E(p \mid c) \mid c^{\prime}\right) \\
& \geq \mathcal{M}^{\infty}\left(E(p \mid c) \mid c^{\prime}\right) \\
& =E\left(p \mid c^{\prime}\right),
\end{aligned}
$$

which proves the result. The first inequality becomes a strict inequality when $E(p \mid c)>$ 0 , which shows the decreasing result.

Proposition 1 (Comparative Statics). If $E(p, c)>0$, equity value is decreasing in the tax rate $\pi$, the coupon $c$, the rate of creative destruction $f$, and the cost $q(p, \lambda, \theta)$ of performing $R \mathscr{E} D$. 
Proof. The result for $c$ and $f$ follows from Lemma 1. Take any other parameter (or the function $q(p, \lambda, \theta))$ and call it $\Xi$. If $E(p \mid \Xi)>0$ then the mapping $\mathcal{M}(E \mid \Xi)$ is decreasing in $\Xi$ and increasing $E$. Therefore,

$$
\begin{aligned}
E(p \mid \Xi) & =\mathcal{M}(E(p \mid \Xi) \mid \Xi) \\
& >\mathcal{M}\left(E(p \mid \Xi) \mid \Xi^{\prime}\right) \\
& \geq \mathcal{M}^{2}\left(E(p \mid \Xi) \mid \Xi^{\prime}\right) \\
& \geq \mathcal{M}^{n>2}\left(E(p \mid \Xi) \mid \Xi^{\prime}\right) \\
& \geq \mathcal{M}^{\infty}\left(E(p \mid \Xi) \mid \Xi^{\prime}\right) \\
& =E\left(p \mid \Xi^{\prime}\right),
\end{aligned}
$$

which proves the result.

\section{B Industry Equilibrium}

First, we establish existence of an industry equilibrium (Theorem 2) and afterwards conditions under which there is a unique rate of creative destruction (Proposition 2).

To establish the existence of an equilibrium, we make the following assumption:

Assumption 1. For the firm value, the order of the limit with respect to $f$ and the supremum over c can be interchanged:

$$
\lim _{f^{\prime} \rightarrow f} \sup _{c}\left\{E\left(p, c \mid f^{\prime}\right)+(1-\xi) D\left(p, c \mid f^{\prime}\right)\right\}=\sup _{c} \lim _{f^{\prime} \rightarrow f}\left\{E\left(p, c \mid f^{\prime}\right)+(1-\xi) D\left(p, c \mid f^{\prime}\right)\right\} .
$$

Theorem 2 (Equilibrium Existence). If the assumption stated in Appendix $B$ holds then there exists an industry equilibrium $\Psi^{*}$.

Proof. The proof has several steps:

1. The first step is showing that the equity value converges to zero when $f \rightarrow \infty$. Assume this is not the case then for some $p E(p \mid f)>0$ when $f \rightarrow \infty$. From equation (3) it follows that for any $p>0$ with $E(p \mid f)>0$

$$
\begin{aligned}
0= & \frac{-r E(p \mid f)+(1-\pi)(p-c)}{f} \\
& +\frac{\max _{(\lambda, \theta)}\left\{\lambda\left(\mathbb{E}^{\theta}[E(\min \{p+x, \bar{p}\})]-E(p \mid f)\right)-(1-\pi) q(p, \lambda, \theta)\right\}}{f} \\
& +p\{E(p-1 \mid f)-E(p \mid f)\} .
\end{aligned}
$$

Given that $E(p \mid f) \leq \bar{p} / r$ and $\lambda \leq \bar{\lambda}$, taking $f \rightarrow \infty$ implies that

$$
0=p\{E(p-1 \mid f=\infty)-E(p \mid f=\infty)\}
$$

and therefore that

$$
E(p \mid f=\infty)=E(p-1 \mid f=\infty)
$$


for any $p$ for which $E(p \mid f=\infty)>0$. Given that $E(0 \mid f=\infty)=0$ this implies that

$$
E(p \mid f=\infty)=0 .
$$

2. The debt value also goes to zero when $f \rightarrow \infty$ since the default time and the recovery value in default go to zero. Therefore, firm value $V(f, \theta)$ and also entrant value $E^{e}(f)$ goes to zero as $f \rightarrow \infty$.

3. Define the firm value as

$$
F\left(p_{0} \mid f, c\right)=E\left(p_{0} \mid f, c\right)+(1-\xi) D\left(p_{0} \mid f, c\right) .
$$

4. By Lemma 1 the equity value is continuous in $f$ and therefore,

$$
\lim _{f^{\prime} \rightarrow f}\left\|E(p \mid f, c)-E\left(p \mid f^{\prime}, c\right)\right\|=0 .
$$

Therefore also the dynamics of $P_{t}$ will be the same under $f$ and $f^{\prime} \rightarrow f$. If the default threshold is the same then

$$
\lim _{f^{\prime} \rightarrow f}\left\|D(p \mid f, c)-D\left(p \mid f^{\prime}, c\right)\right\|=0
$$

since the default times will converge. Since the equity value is continuous in $f$, if the default threshold is not the same then at $f$ shareholders must be exactly indifferent between default and no default. Take an arbitrary small $\epsilon$, because the equity value is decreasing in $c$ for either $c-\epsilon$ or $c+\epsilon$, the default threshold under $f^{\prime} \rightarrow f$ will be the same as the default threshold under $f$ (and $c$ ). Furthermore, because the equity value is continuous in $f$ and $c$ the dynamics of $P_{t}$ will be continuous in both as well. This implies that

$$
\lim _{\epsilon \rightarrow 0} \lim _{f^{\prime} \rightarrow f}\left\|D(p \mid f, c)-D\left(p \mid f^{\prime}, c \pm \epsilon\right)\right\|=0
$$

since the default time will converge. This implies that

$$
\lim _{\epsilon \rightarrow 0} \lim _{f^{\prime} \rightarrow f}\left|F\left(p_{0} \mid f, c\right)-F\left(p_{0} \mid f^{\prime}, c \pm \epsilon\right)\right|=0,
$$

5. The previous step shows that for a given $f, c$, and $f^{\prime} \rightarrow f$ there exists an $c^{\prime}=\lim _{\epsilon \rightarrow 0} c \pm \epsilon$ such that the firm value is continuous in $f$. This implies that

$$
\sup _{c} F\left(p_{0} \mid f^{\prime}, c\right)=\sup _{c} \lim _{f^{\prime} \rightarrow f} F\left(p_{0} \mid f^{\prime}, c\right)=\lim _{f^{\prime} \rightarrow f} \sup _{c} F\left(p_{0} \mid f^{\prime}, c\right) .
$$

The last step follows from Assumption 1. This shows that $\sup _{c} F\left(p_{0} \mid f, c\right)$ is continuous in $f$. 
6. This also implies that,

$$
V(f, \theta)=\mathbb{E}^{\theta}\left[\sup _{c}\left\{F\left(p_{0} \mid f, c\right)\right\}\right]
$$

with $p_{0}=\min (y, \bar{p})$ and $y \sim \operatorname{Bin}(n, \theta)$ is continuous in $f$ and $\theta$.

7. If there exists an $E^{e}(f) \geq H$ then the intermediate value theorem ensures existence of an $f$ such that $E^{e}(f)=H$, which is an industry equilibrium.

8. If for all $f E^{e}(f)<H$ then entry is never optimal. Given the fact that $P_{t}$ is nondecreasing for $f=0$, it follows that $E(p \mid c=0, f=0)>0$. Therefore, a steady state equilibrium exists in which all firms have $\bar{p}$ product lines and no one innovates.

Proposition 2 (Uniqueness of the Rate of Creative Destruction). If the debt value is strictly decreasing in $f$ then all equilibria have the same rate of creative destruction $f^{*}$.

Proof. The proof has several steps:

1. First, we show the entrant value is strictly decreasing in $f$. Since the equity value (for any positive value) and debt value are strictly decreasing in $f$, the optimal firm value $V(f, \theta)$ must be strictly decreasing in $f$ as well. Take an $f_{1}<f_{2}$ then

$$
\begin{aligned}
V\left(f_{2}, \theta\right) & =\mathbb{E}^{\theta}\left[E\left(\min \{x, \bar{p}\} \mid f_{2}, c_{2}\right)+D\left(\min \{x, \bar{p}\} \mid f_{2}, c_{2}\right)\right] \\
& <\mathbb{E}^{\theta}\left[E\left(\min \{x, \bar{p}\} \mid f_{1}, c_{2}\right)+D\left(\min \{x, \bar{p}\} \mid f_{1}, c_{2}\right)\right] \\
& \leq V\left(f_{1}, \theta\right)
\end{aligned}
$$

where $c_{2}$ is the firm value maximizing coupon given $\theta$ and $f_{2}$. Because the entrants value is

$$
E^{e}(f)=\sup _{\{\lambda, \theta\}}\left(\frac{\lambda V(f, \theta)-q_{E}(\lambda, \theta)}{r+\lambda}\right)
$$

it is also strictly decreasing in $V(f, \theta)$.

2. There are now two cases. If $E^{e}(0)<0$ then $E^{e}(f)<H$ for all $f$ and the only equilibrium rate of creative destruction is $f^{*}=0$. If $E^{e}(0)>0$ then there exists a unique $f^{*}$ such that

$$
E^{e}\left(f^{*}\right)=H
$$

which is a condition that needs to be satisfied in equilibrium if $f^{*}>0$. This proves that any equilibrium must have a rate of creative destruction $f^{*}$. 
Proposition 4 (Debt versus No Debt). Let $f_{\text {No Debt }}^{*}$ be the equilibrium rate of creative destruction in case incumbent firms are restricted to have no debt then there exists an industry equilibrium with a rate of creative destruction

$$
f^{*} \geq f_{\text {No Debt }}^{*}
$$

Proof. The proof has several steps:

1. By assumption the option to issue debt increases shareholder value. This implies that,

$$
E^{e}\left(f_{\text {No Debt }}^{*}\right) \geq E_{\text {No Debt }}^{e}\left(f_{\text {No Debt }}^{*}\right)
$$

2. If $f_{N o \text { Debt }}^{*}=0$ then from Theorem 2 it directly follows that there exists an

$$
f^{*} \geq f_{\text {No Debt }}^{*}
$$

3. If $f_{\text {No Debt }}^{*}>0$ then

$$
E^{e}\left(f_{\text {No Debt }}^{*}\right) \geq E_{\text {No Debt }}^{e}\left(f_{\text {No Debt }}^{*}\right)=H .
$$

The proof of Theorem 2 shows that the entrant value is continuous in $f$ and that $\lim _{f \rightarrow \infty} E^{e}(f)=0$. Therefore, there exists an

$$
f^{*} \geq f_{N o \text { Debt }}^{*}
$$

such that

$$
E^{e}\left(f^{*}\right)=H
$$

and this $f^{*}$ is an industry equilibrium.

Proposition 3. (Comparative Statics: No debt case) Let $f_{\text {No Debt }}^{*}$ be the equilibrium rate of creative destruction in case incumbent firms are restricted to have no debt. The equilibrium rate of creative destruction in the No Debt case $f_{\text {NoDebt }}^{*}$ is non-decreasing in the tax rate $\pi$, incumbents' R\&BD cost $q(p, \lambda, \theta)$, entrants $R \mathscr{G} D$ cost $q_{E}(\lambda, \theta)$, and the entry cost $H$.

Proof. The proof has several steps:

1. From Proposition 2 it follows that for given parameters $f_{\text {NoDebt }}^{*}$ is unique.

2. From Theorem 1 it follows that an incumbents equity value, and firm value in the no debt case, are decreasing in $\pi$ and $q$. Furthermore, an entrants' value is decreasing $q_{E}$.

3. Therefore, keeping $f_{\text {NoDebt }}^{*}$ fixed and increasing any of these parameters or $H$ implies that

$$
E_{e}\left(f_{\text {NoDebt }}^{*}\right) \leq H
$$


This result implies that the equilibrium rate of creative destruction cannot be increasing in any of these parameters.

\section{Refinancing}

First, we establish existence of the equity and debt value (Theorem 4). Afterwards, we establish the existence of an industry equilibrium under Assumption 2 (Theorem 3). Finally, under additional conditions we establish uniqueness of the rate of creative destruction (Proposition $5)$.

In this appendix we use the following notation:

$$
E_{K}\left(p, c, p^{I}\right)
$$

is the equity value for a firm that can still restructure its debt $K$ times. The debt value $D_{K}\left(p, c, p^{I}\right)$ and firm value $F_{K}\left(p, c, p^{I}\right)$ are similarly defined. Furthermore,

$$
\begin{aligned}
& E\left(p, c, p^{I}\right)=\lim _{K \rightarrow \infty} E_{K}\left(p, c, p^{I}\right), \\
& D\left(p, c, p^{I}\right)=\lim _{K \rightarrow \infty} D_{K}\left(p, c, p^{I}\right), \\
& F\left(p, c, p^{I}\right)=\lim _{K \rightarrow \infty} F_{K}\left(p, c, p^{I}\right) .
\end{aligned}
$$

Theorem 4. The equity and debt value exist. If the optimal level of R\&D is internal $((\lambda, \theta) \in(0, \bar{\lambda}) \times(0,1))$ then it solves

$$
\begin{aligned}
\mathbb{E}^{\theta}\left[E\left(\min \{p+x, \bar{p}\}, c, p^{I}\right)\right]-E\left(p, c, p^{I}\right) & =(1-\pi) \frac{\partial q(p, \lambda, \theta)}{\partial \lambda}, \\
\lambda \frac{\partial \mathbb{E}^{\theta}\left[E\left(\min \{p+x, \bar{p}\}, c, p^{I}\right)\right]}{\partial \theta} & =(1-\pi) \frac{\partial q(p, \lambda, \theta)}{\partial \theta} .
\end{aligned}
$$

Proof. We establish existence of the equity and debt value recursively.

1. From Theorem 1 it follows that the equity value for a firm that does not have the option to refinance exists. Therefore, also the debt value exists. Let this equity and debt value define the firm value

$$
F_{0}\left(p, c, p^{I}\right)=E_{0}\left(p, c, p^{I}\right)+(1-\xi) D_{0}\left(p, c, p^{I}\right) .
$$

The state variable $p^{I}$ plays no role if the firm cannot restructure.

2. Assume $F_{K-1}\left(p, c, p^{I}\right)$ exists. First, observe the equity value $E_{K}\left(p, c, p^{I}\right)$ does not depend on $D_{K}\left(p, c, p^{I}\right)$ since the price at which the existing debt is bought back is 
$\rho\left(p^{I}\right) c$. The equity value for a firm that has $K$ restructuring options is

$$
\begin{aligned}
E_{K}\left(p, c, p^{I}\right)=\sup _{\left\{\lambda_{t}, \theta_{t}\right\}_{t \geq 0}, \tau_{D}, \tau_{C}}\{ & \mathbb{E}_{p}\left[\int_{0}^{\tau_{D} \wedge \tau_{0} \wedge \tau_{C}} e^{-r t}(1-\pi)\left(P_{t}-c-q\left(P_{t}, \lambda_{t}, \theta_{t}\right)\right) d t\right] \\
& \left.+\mathbb{E}_{p}\left[\mathbb{I}_{\left\{\tau_{C}<\tau_{D} \wedge \tau_{0}\right\}} e^{-r \tau_{C}}\left(\sup _{c^{\prime}>c} F_{K-1}\left(P_{\tau_{C}}, c^{\prime}, P_{\tau_{C}}\right)-\rho\left(p^{I}\right) c\right)\right]\right\} .
\end{aligned}
$$

Given $F_{K-1}\left(p, c, p^{I}\right)$, this implies that the equity value $E_{i}\left(p, c, p^{I}\right)$ is a fixed point of the mapping

$$
\begin{aligned}
\mathcal{M}_{K}(E)=\sup _{\lambda, \theta, \tau_{D}, \tau_{C}}\{ & \mathbb{E}_{p}\left[\int_{0}^{\tau_{D} \wedge \tau_{C}} e^{-(r+\lambda+p f) t}(1-\pi)(p-c-q(p, \lambda, \theta)) d t\right] \\
& \mathbb{E}_{p}\left[\int_{0}^{\tau_{D} \wedge \tau_{C}} e^{-(r+\lambda+p f) t} \lambda \mathbb{E}^{\theta}\left[E\left(\min (p+x, \bar{p}), c, p^{I}\right)\right] d t\right] \\
& \mathbb{E}_{p}\left[\int_{0}^{\tau_{D} \wedge \tau_{0} \wedge \tau_{C}} e^{-(r+\lambda+p f) t} f p E\left(p-1, c, p^{I}\right) d t\right] \\
& \left.+\mathbb{E}_{p}\left[\mathbb{I}_{\left\{\tau_{C}<\tau_{D}\right\}} e^{-(r+\lambda+p f) \tau_{C}}\left(F_{K-1}\left(p, c^{\prime}, p\right)-\rho\left(p^{I}\right) c-\xi\right)\right]\right\}
\end{aligned}
$$

with $E_{K}\left(0, c, p^{I}\right)=0$. The equity value is bounded from above by

$$
\frac{(1-\pi) \bar{p}+\tau \bar{c}}{r}
$$

and from below by zero, it is increasing in $E$, and

$$
\mathcal{M}_{K}(E+L) \leq \mathcal{M}_{K}(E)+\frac{\bar{\lambda}+f \bar{p}}{r+\bar{\lambda}+f \bar{p}} L .
$$

Therefore, the mapping $\mathcal{M}_{K}(E)$ satisfies Blackwell's sufficient conditions for a contraction, see Theorem 3.3 on page 54 in Stokey et al. (1989), and it is a contraction mapping, which implies that a fixed point exists and is unique. Let $E_{K}\left(p, c, p^{I}\right)$ be the fixed point of this mapping.

3. The debt value $D_{K}\left(p, c, p^{I}\right)$ follows from the optimal policies the firm follows and therefore also $F_{K}\left(p, c, p^{I}\right)$. This recursively establishes existence of the value functions.

4. Optimality of an internal R\&D policy implies that they solve the first-order conditions, which shows the last result.

For the proof on equilibrium existence we need the following assumption, which generalizes Assumption 1 for the static debt case: 
Assumption 2. For the firm value, the order of the limit with respect to $f$ and the supremum over c can be interchanged:

$\lim _{f^{\prime} \rightarrow f} \sup _{c}\left\{E_{K}\left(p, c, p \mid f^{\prime}\right)+(1-\xi) D_{K}\left(p, c, p \mid f^{\prime}\right)\right\}=\sup _{c} \lim _{f^{\prime} \rightarrow f}\left\{E_{K}\left(p, c, p \mid f^{\prime}\right)+(1-\xi) D_{K}\left(p, c, p \mid f^{\prime}\right)\right\}$.

Lemma 2. The entrant value $E_{e}(f)$ is continuous in $f$.

Proof. Continuity is shown recursively.

1. From the proof of Theorem 2 it follows that $\sup _{c^{\prime}>c} F_{0}\left(p, c, p^{I} \mid f\right)$ is continuous in $f$ and $c$.

2. Assume $\sup _{c^{\prime}>c} F_{K-1}\left(p, c, p^{I} \mid f\right)$ is continuous in $f$ and $c$. The mapping $\mathcal{M}_{K}(E \mid f)$ is continuous in $f$. Therefore, for every $\epsilon>0$ there exists a $\delta>0$ such that for $f^{\prime} \in(f-\delta, f+\delta)$,

$\left\|\mathcal{M}_{K}\left(E_{K}\left(p, c, p^{I} \mid f\right) \mid f^{\prime}\right)-E_{K}\left(p, c, p^{I} \mid f\right)\right\|=\left\|\mathcal{M}_{K}\left(E_{K}\left(p, c, p^{I} \mid f\right) \mid f^{\prime}\right)-\mathcal{M}_{K}\left(E_{K}\left(p, c, p^{I} \mid f\right) \mid f\right)\right\|<\epsilon$.

Fix one such $\epsilon$. Applying the mapping $\mathcal{M}_{K}$ again leads to,

$\left\|\mathcal{M}_{K}^{2}\left(E_{K}\left(p, c, p^{I} \mid f\right) \mid f^{\prime}\right)-\mathcal{M}_{K}\left(E_{K}\left(p, c, p^{I} \mid f\right) \mid f^{\prime}\right)\right\| \leq U\left\|\mathcal{M}_{K}\left(E_{K}\left(p, c, p^{I} \mid f\right) \mid f^{\prime}\right)-E_{K}(p, c \mid f)\right\|<U \epsilon$.

where,

$$
U=\frac{\bar{\lambda}+\bar{p} f^{\prime}}{r+\bar{\lambda}+\bar{p} f^{\prime}} .
$$

This process can be repeated (where $\mathcal{M}_{K}^{m}(E \mid f)$ means applying the mapping $\mathcal{M}_{K}(\cdot \mid f)$ $m$ times to $E$ ) and leads to

$$
\left\|\mathcal{M}_{K}^{m+1}\left(E_{K}\left(p, c, p^{I} \mid f\right) \mid f^{\prime}\right)-\mathcal{M}_{K}^{m}\left(E_{K}\left(p, c, p^{I} \mid f\right) \mid f^{\prime}\right)\right\|<U^{m} \epsilon .
$$


Therefore the distance between $E_{K}\left(p, c, p^{I} \mid f\right)$ and $E_{K}\left(p, c, p^{I} \mid f^{\prime}\right)$ is bounded by

$$
\begin{aligned}
\left\|E_{K}\left(p, c, p^{I} \mid f\right)-E_{K}\left(p, c, p^{I} \mid f^{\prime}\right)\right\| & =\left\|E_{K}\left(p, c, p^{I} \mid f\right)-\mathcal{M}_{K}^{\infty}\left(E_{K}\left(p, c, p^{I} \mid f\right) \mid f^{\prime}\right)\right\| \\
& \leq \sum_{i=0}^{\infty}\left\|\mathcal{M}_{K}^{i+1}\left(E_{K}\left(p, c, p^{I} \mid f\right) \mid f^{\prime}\right)-\mathcal{M}_{K}^{i}\left(E_{K}\left(p, c, p^{I} \mid f\right) \mid f^{\prime}\right)\right\| \\
& <\epsilon \sum_{i=0}^{\infty} U^{i} \\
& =\epsilon \frac{1}{1-U} \\
& \leq \epsilon \frac{r+\bar{\lambda}+\bar{p}(f+\delta)}{r} .
\end{aligned}
$$

Set $\tilde{\delta}=\min \{\delta, 1\}$ and

$$
\tilde{\epsilon}=\epsilon \frac{r+\bar{\lambda}+\bar{p}(f+1)}{r} .
$$

This implies that for every $\tilde{\epsilon}>0$ there exists a $\tilde{\delta}>0$ such that for $f^{\prime} \in(f-\tilde{\delta}, f+\tilde{\delta})$,

$$
\left\|E_{K}\left(p, c, p^{I} \mid f\right)-E_{K}\left(p, c, p^{I} \mid f^{\prime}\right)\right\|<\tilde{\epsilon} .
$$

Therefore, $E_{K}\left(p, c, p^{I} \mid f\right)$ is continuous in $f$. The same argument shows that $E_{K}\left(p, c, p^{I}\right)$ is continuous in $c$.

3. Since the equity value $E_{K}(p, c, p \mid f)$ is continuous in $f$, similar steps as in the proof of Theorem 2 show that for $F_{K}\left(p_{0}, c, p_{0} \mid f\right)$ there exists an $\epsilon$ such that

$$
\lim _{\epsilon \rightarrow 0} \lim _{f^{\prime} \rightarrow f}\left|F_{K}\left(p_{0}, c, p_{0} \mid f\right)-F_{K}\left(p_{0}, c \pm \epsilon, p_{0} \mid f^{\prime}\right)\right|=0
$$

4. The previous step shows that for a given $f, c$, and $f^{\prime} \rightarrow f$ there exists a coupon $c^{\prime}=\lim _{\epsilon \rightarrow 0} c \pm \epsilon$ such that the firm value is continuous in $f$. This implies that

$$
\sup _{c} F_{K}\left(p_{0}, c, p_{0} \mid f^{\prime}\right)=\sup _{c} \lim _{f^{\prime} \rightarrow f} F_{K}\left(p_{0}, c, p_{0} \mid f^{\prime}\right)=\lim _{f^{\prime} \rightarrow f} \sup _{c} F_{K}\left(p_{0}, c, p_{0} \mid f^{\prime}\right) .
$$

The last step follows from Assumption 2. This shows that $\sup _{c} F\left(p_{0} \mid f, c\right)$ is continuous in $f$.

5. Applying the previous steps recursively ensures that

$$
\sup _{c^{\prime}>c} F_{K}\left(p, c^{\prime}, p \mid f\right)
$$

is continous in $f$. This combined with the fact the firm value for $c=0$ is continuous 
in $f$ ensures that

$$
V\left(f, \theta_{E}\right)=\mathbb{E}^{\theta_{e}}\left[\sup _{c \geq 0}\left\{F\left(p_{0}, c, p_{0}\right)\right\}\right]
$$

is continuous in $f$. This shows that the entrant value $E^{e}(f)$ is continuous in $f$.

Theorem 3 (Equilibrium Existence with Debt Refinancing). If the assumption stated in Appendix $C$ holds then there exists an industry equilibrium $\Psi^{*}$ in the model with debt refinancing.

Proof. The proof has several steps

1. It follows from Theorem 2 that $F_{0}\left(p, c, p^{I}\right)$ converges to zero as $f \rightarrow \infty$. Assume $F_{K-1}$ converges to zero as $f \rightarrow \infty$. Assume this is not the case for $E_{K}\left(p, c, p^{I} \mid f\right)$ then for some $p E_{K}\left(p, c, p^{I} \mid f\right)>0$ when $f \rightarrow \infty$. This directly implies that the firm does not restructure for this $p$. Furthermore, from equation (3) it follows that for any $p>0$ with $E_{K}\left(p, c, p^{I} \mid f\right)>0$

$$
\begin{aligned}
0= & \frac{-r E_{K}\left(p, c, p^{I} \mid f\right)+(1-\pi)(p-c)}{f} \\
& +\frac{\max _{(\lambda, \theta)}\left\{\lambda\left(\mathbb{E}^{\theta}\left[E_{K}\left(\min \{p+x, \bar{p}\}, c, p^{I}\right)\right]-E_{K}\left(p, c, p^{I} \mid f\right)\right)-(1-\pi) q(p, \lambda, \theta)\right\}}{f} \\
& +p\left\{E_{K}\left(p-1, c, p^{I} \mid f\right)-E_{K}\left(p, c, p^{I} \mid f\right)\right\} .
\end{aligned}
$$

Given that $E_{K}\left(p, c, p^{I} \mid f\right) \leq((1-\pi) \bar{p}+\pi \bar{c}) / r$ and $\lambda \leq \bar{\lambda}$, taking $f \rightarrow \infty$ implies that

$$
0=p\left\{E_{K}\left(p-1, c, p^{I} \mid f=\infty\right)-E_{K}\left(p, c, p^{I} \mid f=\infty\right)\right\}
$$

and therefore that

$$
E_{K}\left(p, c, p^{I} \mid f=\infty\right)=E_{K}\left(p-1, c, p^{I} \mid f=\infty\right)
$$

for any $p$ for which $E_{K}\left(p, c, p^{I} \mid f=\infty\right)>0$. Given that $E_{K}\left(0, c, p^{I} \mid f=\infty\right)=0$ this implies that

$$
E_{K}\left(p, c, p^{I} \mid f=\infty\right)=0 .
$$

which converges to zero as $f \rightarrow \infty$. This implies that the firm value and therefore the entrant's value goes to zero as $f \rightarrow \infty$. The debt value also goes to zero when $f \rightarrow \infty$ since the default time and the recovery value in default go to zero. This implies $F_{K}\left(p, c, p^{i}\right)$ goes as $f \rightarrow \infty$.

2. If $\exists f$ such that $E^{e}(f)>H$ then Lemma 2, the previous step, and the intermediate 
value theorem imply there exists an $f^{*}$ such that

$$
E^{e}\left(f^{*}\right)=H,
$$

which is an industry equilibrium.

3. If $\nexists f$ such that $E^{e}(f)>H$ then $f^{*}=0$ is an industry equilibrium.

Proposition 5 (Uniqueness of the Rate of Creative Destruction with Debt Refinancing). If the debt value is strictly decreasing in $f$ then all equilibria with debt refinancing have the same rate of creative destruction $f^{*}$.

Proof. The proof has several steps:

1. From the proof of Proposition 2 it follows that $F_{0}\left(p, c, p^{I}\right)$ is strictly decreasing in $f$

2. Assume $F_{K-1}\left(p, c, p^{I} \mid f\right)$ is strictly decreasing in $f$. Similar proofs as the one in Lemma 1 then ensure that $E_{K}\left(p, c, p^{I} \mid f\right)$ is strictly decreasing in $f$. It then follows that for an $f_{1}<f_{2}$

$$
\begin{aligned}
F_{K}\left(p, c, p^{I} \mid f_{2}\right) & =E_{K}\left(p, c, p_{I} \mid f_{2}\right)+D\left(p, c, p^{I} \mid f_{2}\right) \\
& <E_{K}\left(p, c, p_{I} \mid f_{1}\right)+D\left(p, c, p^{I} \mid f_{1}\right) \\
& F_{K}\left(p, c, p^{I} \mid f_{2}\right)
\end{aligned}
$$

and thus that $F_{K}\left(p, c, p^{I} \mid f\right)$ is strictly decreasing in $f$.

3. Thiis shows that $V\left(f, \theta_{e}\right)$ is strictly decreasing in $f$ and therefore

$$
E^{e}(f)=\sup _{\{\lambda, \theta\}}\left(\frac{\lambda V(f, \theta)-q_{E}(\lambda, \theta)}{r+\lambda}\right)
$$

is also strictly decreasing in $V(f, \theta)$.

4. There are now two cases. If $E^{e}(0)<0$ then $E^{e}(f)<H$ for all $f$ and the only equilibrium rate of creative destruction is $f^{*}=0$. If $E^{e}(0)>0$ then there exists a unique $f^{*}$ such that

$$
E^{e}\left(f^{*}\right)=H,
$$

which is a condition that needs to be satisfied in equilibrium if $f^{*}>0$. This proves that any equilibrium must have a rate of creative destruction $f^{*}$. 


\section{General Equilibrium Setup}

In this appendix, we embed our model into a general equilibrium setup. This endogenizes the growth rate of the economy, the wage rate, and the interest rate. The general equilibrium setup is similar to Klette and Kortum (2004) and leads to a stationary equilibrium with a balanced growth path.

\section{Production}

There is a unit mass of differentiated goods in the economy, which are indexed by $i \in[0,1]$, and a mass $L^{S}$ of labor. A measure $L^{P}$ of labor is used for production, a measure $L^{R \& D}$ of labor performs R\&D, and a meausre $L^{E}$ of labor is used to generate entrants. Labor receives a wage $w$ per unit supplied for all these activities.

Incumbent firms use labor and installed product lines to produce goods. An improvement in the production technology increases the amount of the consumption good that one unit of labor produces.

For each type of product there is a leading producer, as in the industry equilibrium model. The production technology of good $i$ 's leading producer is $q_{t}^{i}$ and determines the number of products that one unit of labor produces.

A firm that innovates on product $i$ improves the production technology and becomes the leading producer. Each innovation is a quality improvement applying to a good drawn at random. The innovation increases the production technology proportionally. That is, when an innovation arrives at time $t$, the production technology increases from $q_{t^{-}}^{i}$ to $q_{t}^{i}=(1+\delta) q_{t^{-}}^{i}$ with $\delta>0$.

A firm that owns the leading patent for product $i$ is a monopolist for that good and can choose to supply or not supply that good. If the firm supplies the good then it uses one unit of labor to generate $q_{t}^{i}$ units of the product. If the firm does not supply the good, its output and profits are zero. ${ }^{8}$

Let $y_{t}^{i}$ be the amount of good $i$ produced at time $t$. As in Klette and Kortum (2004) or Aghion et al. (2005) the aggregate consumption good is produced using a logarithmic aggregator

$$
\ln \left(Y_{t}\right)=\int_{0}^{1} \ln \left(y_{t}^{i}\right) d i
$$

with $Y_{t}$ aggregate production of the consumption good. ${ }^{9}$

${ }^{8}$ We can obtain equivalent results when each production line has as production function $q_{t}^{i}\left(l-\mathbb{I}_{\{l \geq 1\}} k^{\prime}(l-\right.$ 1)) where $k(0)=0$ and $k^{\prime}(\cdot)>0$ and produces the maximum amount of the good among production quantities that maximize his profits.

${ }^{9}$ This is a limiting case of the Dixit-Stiglitz aggregator when the elasticity of substitution $\epsilon$ goes to 1

$$
\lim _{\epsilon \rightarrow 1} \ln \left(\left(\int_{0}^{1}\left(y_{t}^{i}\right)^{\frac{\epsilon-1}{\epsilon}} d i\right)^{\frac{\epsilon}{\epsilon-1}}\right)=\lim _{\epsilon \rightarrow 1} \frac{\ln \left(\int_{0}^{1}\left(y_{t}^{i}\right)^{\frac{\epsilon-1}{\epsilon}} d i\right)}{\frac{\epsilon-1}{\epsilon}}=\lim _{\epsilon \rightarrow 1} \frac{\int_{0}^{1} \ln \left(y_{t}^{i}\right)\left(y_{t}^{i}\right)^{\frac{\epsilon-1}{\epsilon}} d i}{\int_{0}^{1}\left(y_{t}^{i}\right)^{\frac{\epsilon-1}{\epsilon}} d i}=\int_{0}^{1} \ln \left(y_{t}^{i}\right) d t .
$$




\section{Innovation}

The firm can also invest in R\&D. Investment in R\&D leads to product innovations, which improve the amount of a product that one units of labor produces. R\&D investment costs come in the form of labor costs. We assume innovation costs are a function of the wage rate multiplied by the number of hours spend on R\&D:

$$
q(p, \lambda, \theta)=w * \tilde{q}(p, \lambda, \theta) .
$$

Therefore, a firm with $p$ products that has an $\operatorname{R\& D}$ policy $(\lambda, \theta)$ requires $\tilde{q}(p, \lambda, \theta)$ units of labor. ${ }^{10}$ We define the innovation cost function for an entrant in a similar way:

$$
q_{E}(\lambda, \theta)=w * \tilde{q}_{E}(\lambda, \theta)
$$

\section{Default and Entry}

Debt distorts investment in $\mathrm{R} \& \mathrm{D}$ and can lead to default. We assume that if a firm with profitable product lines decides to default then creditors continue producing these goods until the products become obsolete after which they exit. Furthermore, creditors do not perform $\mathrm{R} \& \mathrm{D}$ and run the firm as an all-equity financed firm. Their expected payoff is therefore

$$
\frac{(1-\pi) P_{\tau_{D}}(1-w)}{r+f} .
$$

This setup implies that the debt value is the same as in the industry equilibrium model with $\alpha=0$, see equation (4). In this model, default costs are therefore related to the change in investment policy triggered by default.

Because firms exit, in a stationary equilibrium there must be entry. As in the industry equilibrium model, entrants have no product lines but perform R\&D in the hope of developing innovations, so they obtain a leading patent and can then produce that good. In the industry equilibrium model, entrants pay a fixed entry cost $H$ to become an entrant. In our general equilibrium model, these fixed costs are replaced by labor costs. An entrepreneur can hire one unit of labor, which costs him $w$, and that generates an idea with Poisson intensity $h$. Once the entrepeneur has generated this idea he can become an entrant. This implies that the free entry condition becomes $E^{e}(f)=\frac{w}{h}$, since in equilibrium the cost and benefits should equate for an entrepreneur

$$
E^{e}(f) h=w .
$$

\footnotetext{
${ }^{10}$ The condition on the $\mathrm{R} \& \mathrm{D}$ cost that ensures that the equity value is non-decreasing in $p$, see (1), in the general equilibrium framework boils down to

$$
q(p+1, \lambda, \theta)-q(p+1, \lambda, \theta) \leq 1-w
$$
}




\section{Representative Household}

There is a representative household with logarithmic preferences:

$$
U_{0}=\int_{0}^{\infty} e^{-\rho t} \ln \left(\mathcal{C}_{t}\right) d t
$$

where $\mathcal{C}_{t}$ is aggregate consumption and $\rho$ is the discount rate. The representative household inelastically supplies the $L_{S}>1$ unit of labor.

\section{Equilibrium Properties}

Since our model is a closed economy and all costs come in the form of labor costs, consumption equals production for each good $i$, and therefore aggregate consumption and production are also equal

$$
\mathcal{C}_{t}=Y_{t}
$$

The logarithm of aggregate consumption $\ln \left(\mathcal{C}_{t}\right)$ is the numeraire in this economy. The representative household owns all (financial) assets in the economy and receives all labor income.

Using the logarithm of consumption $\ln \left(\mathcal{C}_{t}\right)$ as the numeraire, the representative household's optimal consumption across goods implies that the price of good $i$ should be

$$
\frac{1}{y_{t}^{i}}=p_{t}^{i}
$$

where the marginal benefit of good $i$ is equal to its marginal cost. The average cost of production are

$$
\frac{w}{q_{t}^{i}}
$$

Therefore, the profits on product $i$ are given by

$$
\pi_{t}^{i}=q_{t}^{i}\left(\frac{1}{q_{t}^{i}}-\frac{w}{q_{t}^{i}}\right)=1-w
$$

This definition of the cost function implies that the equity value is as in the industry equilibrium framework (see equation (2)), only now the profit flow from a product line is $1-w$ instead of 1 and the R\&D cost depend on the wage rate $w$ (see equation (7)).

In equilibrium, the growth rate $g$, the interest rate $r$, and wage rate $w$ are determined by market clearing. Since we use the logarithm of consumption as the numeraire, the agent is effectively risk-neutral in the numeraire and therefore, ${ }^{11}$

$$
r=\rho .
$$

\footnotetext{
${ }^{11}$ The risk-free interest rate $r$ should be set such that a household is indifferent between consuming today or tomorrow. Given that there is no aggregate uncertainty, the Hamiltonian for the consumption smoothing problem, with $\hat{\mathcal{C}}_{t}=\ln \left(\mathcal{C}_{t}\right)$ logarithm of aggregate consumption, $\hat{Y}_{t}=\ln \left(Y_{t}\right)$ logarithm of aggregate production,
} 
Consumption grows at a rate of

$$
d \ln \left(\mathcal{C}_{t}\right)=d \int_{0}^{1} \ln \left(y_{t}^{i}\right) d i=\ln (1+\delta) f d t=g d t
$$

where $f$ is the rate of creative destruction in the economy, which results from innovations by incumbents and entrants.

Finally, there is a labor supply $L^{S}$ which is used for production $L^{P}$, R\&D by incumbents $L^{R \& D}$, and $R \& D$ by entrants $L^{e}$ :

$$
\begin{aligned}
L^{P} & =1, \\
L^{R \& D} & =\int_{\mathcal{F}_{t}^{I}} \tilde{q}\left(P_{t}^{j}, \lambda_{t}^{j}, \theta_{t}^{j}\right) d j+\tilde{q}_{E}\left(\lambda_{E}, \theta_{E}\right) \int_{\mathcal{F}_{t}^{E}} d j .
\end{aligned}
$$

where subscript $j$ indicates firm $j, \mathcal{F}_{t}^{I}$ is the set of active incumbents, and $\mathcal{F}_{t}^{E}$ is the set of active entrants. The wage is set such that the labor market clears:

$$
L^{P}+L^{R \& D}+L^{E}=L^{S} .
$$

The wage rate is set such that the labor market clears. When labor demand exceeds supply then wages increases, which makes $R \& D$ more expensive and production less profitable and therefore depreciates demand for labor, and vice versa when labor supply exceeds demand.

The utility of the representative household is

$$
U_{0}=\int_{0}^{\infty} e^{-\rho t}\left(\ln \left(\mathcal{C}_{0}\right)+g t\right) d t=\frac{\ln \left(\mathcal{C}_{0}\right)}{\rho}+\left[\frac{-1}{\rho} e^{-\rho t} g t\right]_{0}^{\infty}+\int_{0}^{\infty} \frac{1}{\rho} e^{-\rho t} g d t=\frac{\rho \ln \left(\mathcal{C}_{0}\right)+g}{\rho^{2}} .
$$

The higher the growth rate in the economy the higher the representative household's utility.

$S_{t}$ savings, and $\kappa_{t}$ the co-state, is

$$
H(\hat{\mathcal{C}}, \hat{Y}, S, r, \kappa, t)=e^{-\rho t} u(\hat{\mathcal{C}})+\kappa[r S+\hat{Y}-\hat{\mathcal{C}}]
$$

where

$$
u(\hat{\mathcal{C}})=\hat{\mathcal{C}}=\ln (\mathcal{C}) .
$$

The optimal solution satisfies the following conditions

$$
\begin{aligned}
& H_{\hat{\mathcal{C}}}\left(\hat{\mathcal{C}}_{t}, \hat{Y}_{t}, S_{t}, r_{t}, \kappa_{t}, t\right)=e^{-\rho t} u^{\prime}\left(\hat{\mathcal{C}}_{t}\right)-\kappa_{t}=0, \\
& H_{s}\left(\hat{\mathcal{C}}_{t}, \hat{Y}_{t}, S_{t}, r_{t}, \kappa_{t}, t\right)=\kappa_{t} r_{t}=-\frac{d \kappa_{t}}{d t},
\end{aligned}
$$

see Chapter 7 in Acemoglu (2009). Taking the total derivative yields

$$
\begin{aligned}
0 & =-\rho e^{-\rho t} u^{\prime}\left(\hat{\mathcal{C}}_{t}\right) d t+e^{-\rho t} u^{\prime \prime}\left(\hat{\mathcal{C}}_{t}\right) d \hat{\mathcal{C}}_{t}-d \kappa_{t} \\
& =-\rho \kappa_{t} d t+0+r_{t} \kappa_{t} d t \\
r_{t} & =\rho,
\end{aligned}
$$

which is the Euler equation that the interest rate $r_{t}$ solves. As we show later, consumption grows at a constant rate and therefore the interest rate is constant over time $r_{t}=r$. 
The formal equilibrium definition is

Definition 2 (General Equilibrium). The parameters and policies

$$
\Psi^{*}=\left\{g^{*}, w^{*}, r^{*}, f^{*}, c^{*}\left(p_{0}\right), \lambda^{*}\left(p \mid p_{0}\right), \theta^{*}\left(p \mid p_{0}\right), p_{D}^{*}\left(p_{0}\right), \lambda_{e}^{*}, \theta_{e}^{*}\right\}
$$

are a general equilibrium if:

1. Incumbents: Given $\left(g^{*}, w^{*}, f^{*}, r^{*}, c^{*}\left(p_{0}\right)\right)$, incumbents production decision, level of $R \mathscr{E D}\left(\lambda^{*}\left(p \mid p_{0}\right), \theta^{*}\left(p \mid p_{0}\right)\right)$, and default decision $p_{D}^{*}\left(p_{0}\right)$ maximize their equity value.

2. Entrants: Given $\left(g^{*}, w^{*}, f^{*}, r^{*}\right)$, entrants level of $R \& D\left(\lambda_{e}^{*}, \theta_{e}^{*}\right)$ and capital structure upon becoming an incumbent $c^{*}\left(p_{0}\right)$ maximize their equity value.

3. Entry: Free entry condition holds:

$$
E^{e}\left(f^{*}\right) \leq \frac{w^{*}}{h}
$$

and the inequality binds when there is creative destruction $f^{*}>0$.

4. Labor: The wage rate $w^{*}$ ensures that the labor market clears:

$$
L^{P}+L^{R \& D}+L^{E}=L^{S} .
$$

5. Growth and interest rate: The growth an interest rate follow from the Euler equation and the rate of creative destruction:

$$
\begin{aligned}
d \ln \left(\mathcal{C}_{t}\right) & =g^{*} d t=\ln (1+\delta) f^{*} d t \\
r^{*} & =\rho .
\end{aligned}
$$

